\title{
Lactifluus (Russulaceae) diversity in Central America and the Caribbean: melting pot between realms
}

\author{
L. Delgat ${ }^{1,}$, R. Courtecuisse ${ }^{2}$, E. De Crop ${ }^{1}$, F. Hampe ${ }^{3}$, T.A. Hofmann ${ }^{4}$, \\ C. Manz ${ }^{5}$, M. Piepenbring ${ }^{5}$, M. Roy ${ }^{6}$, A. Verbeken ${ }^{1}$
}

Key words

Antilles

Basidiomycota

ectomycorrhizal fungi

French West Indies

integrative taxonomy

Latin America

Middle America

new taxa

Russulales

\begin{abstract}
Species of the ectomycorrhizal genus Lactifluus, and often entire sections, are typically unique to a single continent. Given these biogeographic patterns, an interesting region to study their diversity is Central America and the Caribbean, since the region is closely connected to and often considered a part of the North American continent, but biogeographically belong to the Neotropical realm, and comprises several regions with different geologic histories. Based on a multi-gene phylogeny and morphological study, this study shows that Central America, Mexico and the Caribbean harbour at least 35 Lactifluus species, of which 33 were never reported outside of this region. It was found that species from the Caribbean generally show affinities to South American taxa, while species from the Central American mainland generally show affinities to Northern hemispheric taxa. We hypothesise that host specificity and/or climate play a crucial role in these different origins of diversity. Because of these different affinities, Caribbean islands harbour a completely different Lactifluus diversity than the Central American mainland. The majority of species occurring on the islands can be considered endemic to certain islands or island groups. In this paper, detailed morphological descriptions are given, with a focus on the unique diversity of the islands, and identification keys to all hitherto described Lactifluus species occurring in Central America and the Caribbean are provided. One new section, Lactifluus sect. Nebulosi, and three new species, Lactifluus guadeloupensis, Lactifluus lepus and Lactifluus marmoratus are described.
\end{abstract}

Article info Received: 4 July 2019; Accepted: 9 March 2020; Published: 12 June 2020.

\section{INTRODUCTION}

The Russulaceae family represents a dominant group of ectomycorrhizal fungi in almost all forest ecosystems worldwide. In 2008, molecular research showed that the traditionally recognised genera Russula and Lactarius were not monophyletic, resulting in a rearrangement of the generic landscape into four separate genera; Lactarius sensu novo, Russula, Multifurca and Lactifluus (Buyck et al. 2008, 2010). The genus Lactifluus comprises around 200 described species worldwide, although its total diversity is estimated to be much higher, and has its highest species richness in the tropics (De Crop 2016). Lactifluus species, and often sections, are usually unique to a single continent, so there is little to no overlap in species diversity between continents.

Central America, part of Mexico, and the Caribbean present a geographically interesting area to study, since they are often considered part of the North American continent and are closely connected to it, but biogeographically belong to the Neotropical

\footnotetext{
Ghent University, Department of Biology, Research group Mycology, K.L. Ledeganckstraat 35, 9000 Ghent, Belgium; corresponding author e-mail: lynn.delgat@ugent.be.

2 Université Lille Nord France, Faculté des Sciences Pharmaceutiques \& Biologiques, F-59006 Lille, France.

3 Straße des Friedens 11, 99330 Gräfenroda, Germany.

4 Vicerrectoría de Investigación y Posgrado, Centro de Investigaciones Micológicas (CIMi), Herbario UCH, Universidad Autónoma de Chiriquí, 0427 David, Panamá

5 Goethe University, Department of Biological Sciences, Research group Mycology, Max-von-Laue-Str. 13, 60438 Frankfurt am Main, Germany.

6 Université Toulouse 3 Paul Sabatier, CNRS, ENFA, UMR5174 EDB (Laboratoire Évolution \& Diversité Biologique), 118 route de Narbonne, 31062 Toulouse, France.
}

realm together with the South American continent. Given the biogeographic patterns in Lactifluus, the question arises whether species occurring in Central America and the Caribbean are most closely related to North or to South American species.

Most of Central America and the Caribbean is situated on the Caribbean plate. Cuba is an exception as it originated on the Caribbean plate but became stuck on the North American plate. The northern part of Hispaniola is a piece of Cuba that was sheared off as the Caribbean plate moved eastward. The Central American mainland is located on the western edge of this plate and consists of seven countries: Belize, Costa Rica, EI Salvador, Guatemala, Honduras, Nicaragua and Panama. It is a tectonically active region and the landscape of the mainland of Central America is strongly determined by mountain ranges. The region contains diverse forest types: tropical moist broadleaf forests, tropical dry broadleaf forests, tropical coniferous forests and montane forests. The tropical lowlands of Central America are dominated by plants of South American origin, examples of ectomycorrhizal hosts are Coccoloba, Guapira, Neea and Pisonia. This lowland vegetation strongly differs from the montane vegetation, which includes mainly species with temperate North American origins, such as Alnus, Pinus and Quercus. In addition, the southern part of Mexico also belongs to the Neotropical realm, and consists of habitats similar to those present in Central America.

Central America is bordered in the east by the Caribbean Sea. The Caribbean islands comprise two main geographical groups: the Greater Antilles and the Lesser Antilles, which have independent origins. The Antilles are mostly volcanic in origin, arisen due to the subduction of the North American plate under the Caribbean plate. The Greater Antilles are geologically the oldest and lie along the Northern edge of the Caribbean plate.

○ 2020 Naturalis Biodiversity Center \& Westerdijk Fungal Biodiversity Institute

You are free to share - to copy, distribute and transmit the work, under the following condition :

Non-commercial: $\quad$ You may not use this work for commercial purposes.

No derivative works: You may not alter, transform, or build upon this work.

For any reuse or distribution, you must make clear to others the license terms of this work, which can be found at http://creativecommons.org/licenses/by-nc-nd/3.0/legalcode. Any of the above conditions can be waived if you get permission from the copyright holder. Nothing in this license impairs or restricts the author's moral rights. 
They comprise the islands of Cuba, Cayman Islands, Jamaica, Hispaniola (i.e., Dominican Republic and Haiti), Puerto Rico and the Virgin Islands. The largest Greater Antillean islands are Cuba, Hispaniola and Jamaica. Several different forest types occur on the Greater Antilles, such as lowland forests (e.g., rainforests with Carapa guianensis; semi-deciduous forests with Coccoloba diversifolia, Guapira fragrans; seasonal evergreen forests with Ceiba pentandra), submontane forests (e.g., rainforests with Cecropia peltata, Dacryodes excelsa, Mora abbottii, Oxandra laurifolia, Sloanea berteriana; pine forests with Pinus caribaea, Pinus cubensis; sclerophyllous forest with Coccoloba retusa, Quercus oleoides subsp. sagraeana) and montane forests (e.g., rainforests with Alchornea latifolia, Magnolia spp., Ocotea ekmanii, Solanum acropterum; (mixed) pine forests with Pinus cubensis, Pinus occidentalis) (Panagopoulos 1999).

The Lesser Antilles on the other hand are a series of small islands on the eastern edge of the Caribbean plate. The major part of the Lesser Antilles is volcanic in origin, though a small group of islands (i.e., Antigua and Barbuda, Grande-Terre of Guadeloupe, Marie-Galante and Barbados) is of coral (calcareous) origin, building an arc dorsally contiguous to the main volcanic one. This yields a special interest to Guadeloupe, which comprises both ecologies (i.e., volcanic for Basse-Terre and calcareous for Grande-Terre). In contrast, Trinidad and Tobago are continental islands that were cut off by sea level rise from the South American mainland while the other islands emerged from the ocean floor. Trinidad, Guadeloupe and Martinique are the largest Lesser Antillean islands. Vegetation of the Lesser Antilles has been studied in detail, and according to the literature the forests can be classified in four main types:

1. altitudinal, montane or cloud forest;

2. hygrophytic or submontane rain forest;

3. mesophytic or (semi-)evergreen seasonal forest; and

4. xerophytic or tropical semi-deciduous forest.

Montane forests occupy small areas near the highest mountains of Martinique and the vegetation consists of shrubs, most typically Clusia plukenetii. In hygrophytic forests, the annual rainfall is over $2700 \mathrm{~mm} /$ year and a pronounced dry season is absent. In these forests, epiphytes are abundant and tree species are virtually all evergreen. Dominant tree species include Dacryodes excelsa, and the endemic Licania ternatensis, Magnolia dodecapetala and Sloanea massonii. Mesophytic forests have a lower annual rainfall and are characterised by species of Inga, Nectandra, Simarauba and Tabebuia, but patches of several ectomycorrhizal Coccoloba spp. are also present. In xerophytic forests annual rainfall is lower than $1250 \mathrm{~mm} /$ year and there is a distinct dry season. Approximately half of the tree species are deciduous and the canopy commonly consists of species of Bursera, Ceiba, Coccoloba, Guapira, Lonchocarpus, and Pisonia (Stehle 1947, Beard 1948, Pegler \& Fiard 1983, Panagopoulos 1999, Joseph 2013). Coccoloba, Guapira and Pisonia are known ectomycorrhizal hosts (e.g., Tedersoo et al. 2010, Alvarez-Manjarrez et al. 2018) and it is in these xerophytic forests that ectomycorrhizal fungi predominate (Pegler \& Fiard 1983).

Extensive collections of agaricoid Basidiomycota were made on the Lesser Antilles, making it the best studied region in Central America and the Caribbean, and a total of ten Lactarius species were recorded in this area (Pegler \& Fiard 1979, 1983). Recently, most of these species have been combined in Lactifluus (Montoya et al. 2012, Verbeken et al. 2012). However, these species are in need of a thorough molecular study. Other areas in Central America and the Caribbean have been studied less intensively, yielding only three species of Lactifluus described from the Greater Antilles, one Lactifluus species from Central America and four species from southern Mexico (Singer 1973,
Montoya et al. 1996, 2012, Miller et al. 2000, Montoya \& Bandala 2004, Crous et al. 2019, Delgat et al. 2019).

In this paper, a phylogeny based on multiple loci, detailed morphological information and identification keys for Lactifluus species occurring in the Caribbean, and Central America and Mexico are provided. Three new species are described here: Lactifluus guadeloupensis, ${ }^{*}$ L. lepus and L. marmoratus. A new section, $L$. sect. Nebulosi is described, $L$. castaneibadius and $L$. murinipes are synonymised, and Lactarius coccolobae, Lactarius fuscomarginatus, Lactarius pegleri and Lactarius sect. Panuoidei are combined in Lactifluus.

( ${ }^{*}$ L. $=$ Lactifluus)

\section{MATERIAL AND METHODS}

\section{Sampling}

Collections for the Lesser Antilles were made during regular fieldtrips to the islands Martinique and Guadeloupe between 2003 and 2015, organised within the program 'Les champignons des Petites Antilles: diversité, écologie et protection' initiated and conducted by R. Courtecuisse and permitted since 2006 by grants and funding from different organizations (see Acknowledgements). Field work focused on different habitats such as xero-, meso- and hygrophytic forests. The collections from Western Panama were obtained during a field trip to Chiriquí province in 2018 , sampling mostly montane forests, but to a lesser extent also lowlands. Herbarium vouchers were gathered for other regions.

\section{Morphological analysis}

Macroscopic characters were observed from fresh material, with colour codes referring to Kornerup \& Wanscher (1978). Microscopic characters were observed from dried material. Basidiospores were mounted in Melzer's reagent and hymenium, pileipellis and stipitipellis were studied in Congo red in L4. The basidiospore measurements (i.e., length, width and $\mathrm{Q}=$ quotient of length and width) are given as [Ava-2xSDa]Ava $-A v b-[A v b+2 x S D b]$, in which Ava = lowest mean value for the measured specimens, $A v b=$ greatest mean value, $\mathrm{SDa} / \mathrm{b}=$ standard deviation of the lowest and greatest mean value, respectively (number of spores measured per specimen $=15-20$ ). If there was only one specimen, measurements are given as $[A v-2 x S D]-A v-[A v+2 x S D]$. Basidiospores were measured in side view excluding ornamentation. Measurements of basidia, cystidia and pileipellis terminal elements are given as $[A v-2 x S D]-A v-[A v+2 x S D]$, based on minimum 10 measurements per structure and species. Measurements of basidia do not include sterigmata. Line drawings were made with the aid of a drawing tube at following magnifications: $6000 \times$ for spores (Zeiss Axio Scope 2 microscope), $1500 \times$ for other hymenial elements and sections (Olympus cx31 microscope).

\section{Molecular analysis}

DNA was extracted from fresh material preserved in CTAB (Cetyl trimethylammonium bromide) using the CTAB extraction method described in Nuytinck \& Verbeken (2003). The protocol described by Dentinger et al. (2010) was used for dried collections from Kew herbarium, a modified CTAB protocol (Tel-Zur et al. 1999; modified by Agentschap Plantentuin Meise) was used for other dried collections. PCR amplification protocols follow Le et al. (2007). Four nuclear markers previously shown as informative within this genus (Stubbe et al. 2010, Van de Putte et al. 2010, Montoya et al. 2012) were used:

1. the internal transcribed spacer region of ribosomal DNA (ITS), comprising the ITS1 and ITS2 spacer regions and the ribosomal gene $5.8 \mathrm{~S}$, using primers ITS-1F and ITS4 (White et al. 1990, Gardes \& Bruns 1993); 
Table 1 Specimens and GenBank accession numbers of DNA sequences used in the molecular analyses.

\begin{tabular}{|c|c|c|c|c|c|c|}
\hline \multirow[b]{2}{*}{ Species } & \multirow[b]{2}{*}{ Herbariumnumber } & \multirow[b]{2}{*}{ Herbarium } & \multicolumn{4}{|c|}{ GenBank accession numbers } \\
\hline & & & ITS & LSU & $R P B 2$ & $R P B 1$ \\
\hline Lactarius fuliginosus & MTB 97-24 & GENT & JQ446111 & JQ446180 & JQ446240 & KR364392 \\
\hline Lactarius hatsudake & FH 12-052 & GENT & KR364085 & KR364215 & KR364285 & KR364411 \\
\hline Lactarius miniatescens & AV $11-177$ & GENT & KR364059 & KR364187 & KR364315 & KR364443 \\
\hline Lactarius olympianus & ED 08-018 & GENT & KR364089 & KR364220 & KR364320 & KR364448 \\
\hline Lactarius scrobiculatus & JN 2001-058 & GENT & KF432968 & - & KR364344 & KR364474 \\
\hline Lactarius tenellus & ADK 3598 & GENT & KF133280 & KF133313 & KF133345 & KR364482 \\
\hline Lactifluus acicularis & KVP 08-002 & GENT & HQ318226 & HQ318132 & HQ328869 & JN389131 \\
\hline Lactifluus acrissimus & EDC $11-112$ & GENT & KR364041 & KR364168 & KR364254 & KR364366 \\
\hline Lactifluus albomembranaceus & EDC 12-046 & GENT & KR364064 & KR364193 & KR364257 & KR364369 \\
\hline Lactifluus allardii & JN 2004-008 & GENT & KF220016 & KF220125 & KF220217 & KR364370 \\
\hline Lactifluus ambicystidiatus & HKAS J7008 & HKAS & KR364108 & KR364239 & KR364309 & KR364437 \\
\hline Lactifluus annulatoangustifolius & BB $00-1518$ & GENT, PC & AY606981 & KR364253 & - & - \\
\hline Lactifluus annulifer & $\begin{array}{l}\text { TH } 9014 \\
\text { G4819 }\end{array}$ & $\begin{array}{l}\text { BRG, DUKE } \\
\text { PC }\end{array}$ & $\begin{array}{l}\text { KC155376 } \\
\text { KM073086 }\end{array}$ & $\begin{array}{l}\text { KC155376 } \\
-\end{array}$ & $\begin{array}{l}- \\
-\end{array}$ & $\begin{array}{l}- \\
-\end{array}$ \\
\hline Lactifluus armeniacus & EDC 14-501 & MFLU, GENT & KR364127 & - & - & - \\
\hline Lactifluus aurantiifolius & AV 94-063 & GENT & KR364017 & KR364144 & - & - \\
\hline Lactifluus aureifolius & AV 11-074 & GENT & KR364056 & KR364183 & KR364259 & KR364371 \\
\hline Lactifluus auriculiformis & AV $12-050$ & GENT & KR364086 & KR364216 & KR364260 & KR364372 \\
\hline Lactifluus bertillonii & JN 2012-016 & GENT & KR364087 & KR364217 & KR364261 & KR364373 \\
\hline Lactifluus bhandaryi & TENN 051830 & TENN & KR364111 & KR364140 & - & - \\
\hline Lactifluus bicapillus & EDC 12-176 & GENT & KR364070 & KR364199 & KR364300 & KR364428 \\
\hline Lactifluus bicolor & DS 06-247 & GENT & JN388955 & JN388987 & JN375590 & JN389186 \\
\hline Lactifluus brachystegiae & AV 99-002 & GENT & KR364018 & KR364145 & KR364262 & KR364374 \\
\hline Lactifluus brunellus & TH 9130 & BRG, DUKE & JN168728 & - & - & - \\
\hline Lactifluus brunneocarpus & AB 305 & GENT & KR364035 & KR364162 & KR364343 & KR364473 \\
\hline Lactifluus brunneoviolascens & AV 13-038 & GENT & KR364123 & KR364246 & KR364264 & KR364376 \\
\hline Lactifluus brunnescens & AV $05-083$ & GENT & KR364019 & KR364146 & KR364263 & KR364375 \\
\hline Lactifluus caribaeus & $\begin{array}{l}\text { CL/MART06.014 } \\
\text { J.P. Fiard 818A } \\
\text { J.P. Fiard 827B }\end{array}$ & $\begin{array}{l}\text { LIP } \\
\mathrm{K} \\
\mathrm{K}\end{array}$ & $\begin{array}{l}\text { MK046841 } \\
\text { MK046852 } \\
\text { MK046853 }\end{array}$ & $\begin{array}{l}\text { MK046791 } \\
- \\
-\end{array}$ & $\begin{array}{l}- \\
- \\
-\end{array}$ & $\begin{array}{l}- \\
- \\
-\end{array}$ \\
\hline Lactifluus carmineus & AV 99-099 & GENT & KR364131 & KR364251 & KR364265 & - \\
\hline Lactifluus castaneibadius & J.P. Fiard 837A & $\mathrm{K}$ & MK046854 & - & - & - \\
\hline Lactifluus chamaeleontinus & JD 946 & MEISE & KR364079 & KR364208 & KR364267 & KR364377 \\
\hline Lactifluus chiapanensis & Bandala 4374a & GENT & GU258297 & GU265580 & GU258316 & KR364378 \\
\hline Lactifluus chrysocarpus & LE 253907 & LE & $J X 442761$ & JX442761 & - & - \\
\hline Lactifluus clarkeae & MN 2004002 & $\mathrm{~L}$ & KR364011 & HQ318205 & KR364268 & KR364379 \\
\hline Lactifluus coccolobae & OKM-27240 & CFMR & MK774805 & - & - & - \\
\hline Lactifluus cocosmus & ADK 4462 & GENT & KR364013 & KR364141 & KR364269 & KR364380 \\
\hline Lactifluus conchatulus & LTH 457 & GENT & GU258296 & GU265659 & GU258399 & KR364381 \\
\hline Lactifluus corrugis & $\begin{array}{l}\text { AV 05-392 } \\
\text { SAA12 L2 }\end{array}$ & $\begin{array}{l}\text { GENT } \\
\text { GENT }\end{array}$ & $\begin{array}{l}\text { JQ753822 } \\
\text { KR364088 }\end{array}$ & $\begin{array}{l}\text { KR364143 } \\
\text { KR364218 }\end{array}$ & $\begin{array}{l}\text { JQ348127 } \\
\text { KR364361 }\end{array}$ & KR364491 \\
\hline Lactifluus crocatus & KVP 08-034 & GENT & HQ318243 & HQ318151 & HQ328888 & JN389145 \\
\hline Lactifluus cyanovirescens & JD 988 & GENT & KR364082 & KR364211 & KR364270 & KR364382 \\
\hline Lactifluus denigricans & EDC 11-218 & GENT & KR364051 & KR364178 & KR364272 & KR364384 \\
\hline Lactifluus densifolius & AV $11-111$ & GENT & KR364057 & KR364184 & KR364273 & KR364385 \\
\hline Lactifluus dissitus & AV-KD-KVP 09-134 & GENT & JN388978 & JN389026 & JN375628 & JN389172 \\
\hline Lactifluus distantifolius & LTH 288 & GENT & HQ318274 & HQ318193 & KR364274 & JN389155 \\
\hline Lactifluus domingensis & $\begin{array}{l}\text { ANGE1035 } \\
\text { ANGE542 } \\
\text { ANGE837 } \\
\text { ANGE838 }\end{array}$ & $\begin{array}{l}\text { JBSD } \\
\text { JBSD } \\
\text { JBSD } \\
\text { JBSD }\end{array}$ & $\begin{array}{l}\text { MK931340 } \\
\text { MK931339 } \\
\text { MK931342 } \\
\text { MK931341 }\end{array}$ & $\begin{array}{l}\text { MN128988 } \\
\text { MN128987 } \\
\text { MN128989 } \\
\text { MN128990 }\end{array}$ & $\begin{array}{l}\text { MK937131 } \\
\text { MK937130 } \\
\text { MK937133 } \\
\text { MK937132 }\end{array}$ & $\begin{array}{l}- \\
- \\
\text { MN128629 } \\
-\end{array}$ \\
\hline Lactifluus dwaliensis Asia & LTH 55 & GENT & KF220111 & KF220204 & KF220278 & KR364386 \\
\hline Lactifluus edulis & FN 05-628 & GENT & KR364020 & KR364147 & KR364275 & KR364387 \\
\hline Lactifluus flammans & JD 941 & MEISE & KR364078 & KR364207 & KR364303 & KR364431 \\
\hline Lactifluus flocktonae & JET1006 & MEL & JX266621 & JX266637 & - & - \\
\hline Lactifluus foetens & ADK 2840 & MEISE & KR364023 & KR364150 & KR364279 & KR364391 \\
\hline Lactifluus fuscomarginatus & $\begin{array}{l}\text { LM4719 } \\
\text { LM } 4379\end{array}$ & $\begin{array}{l}X A L \\
X A L\end{array}$ & $\begin{array}{l}\text { HQ168368 } \\
\text { HQ168367 }\end{array}$ & - & $\begin{array}{l}- \\
-\end{array}$ & - \\
\hline Lactifluus genevievae & GG-DK 17-02-05 & GENT & GU258294 & GU265657 & GU258397 & KR364401 \\
\hline Lactifluus gerardii & $\begin{array}{l}\text { AV 05-375 } \\
\text { JN 2007-029 }\end{array}$ & $\begin{array}{l}\text { GENT } \\
\text { GENT }\end{array}$ & $\begin{array}{l}\text { GU258254 } \\
\text { GU258224 }\end{array}$ & $\begin{array}{l}\text { GU265616 } \\
\text { GU265582 }\end{array}$ & $\begin{array}{l}\text { GU258353 } \\
\text { GU258318 }\end{array}$ & $\begin{array}{l}\text { KR364403 } \\
-\end{array}$ \\
\hline Lactifluus glaucescens & LGAM 2010-0132 & LGAM-AUA & KR364105 & KR364236 & KR364280 & KR364407 \\
\hline Lactifluus guadeloupensis & RC/Guad11-023 & LIP & KP691412 & KP691421 & KP691430 & - \\
\hline Lactifluus guanensis & GUA-104 & CFMR & MK046851 & - & - & - \\
\hline Lactifluus gymnocarpus & EDC 12-047 & GENT & KR364065 & KR364194 & KR364282 & KR364408 \\
\hline Lactifluus hallingii & $\begin{array}{l}\text { R. E. Halling } 4977 \\
\text { R. E. Halling } 7993 \\
\text { NVE } 520 \\
\text { R. E. Halling } 7938 \\
\text { FH 18-077 }\end{array}$ & $\begin{array}{l}\text { NY } \\
\text { NY } \\
\text { NY } \\
\text { GENT }\end{array}$ & $\begin{array}{l}\text { MK931343 } \\
\text { MK931333 } \\
\text { KF937338 } \\
\text { MK931327 } \\
\text { MK931338 }\end{array}$ & $\begin{array}{l}- \\
- \\
- \\
\text { MN128984 } \\
\text { MN128991 }\end{array}$ & $\begin{array}{l}- \\
\text { MK937128 } \\
- \\
\text { MK937127 } \\
\text { MK937129 }\end{array}$ & $\begin{array}{l}- \\
- \\
- \\
- \\
\text { MN128628 }\end{array}$ \\
\hline Lactifluus hygrophoroides & AV $05-251$ & GENT & HQ318285 & HQ318208 & HQ328936 & KR364413 \\
\hline
\end{tabular}


Table 1 (cont.)

\begin{tabular}{|c|c|c|c|c|c|c|}
\hline \multirow[b]{2}{*}{ Species } & \multirow[b]{2}{*}{ Herbariumnumber } & \multirow[b]{2}{*}{ Herbarium } & \multicolumn{4}{|c|}{ GenBank accession numbers } \\
\hline & & & ITS & LSU & $R P B 2$ & $R P B 1$ \\
\hline Lactifluus igniculus & LE 262983 & LE & JX442759 & JX442759 & - & - \\
\hline Lactifluus kigomaensis & AV 11-006 & GENT & KR364052 & KR364179 & KR364288 & KR364415 \\
\hline Lactifluus kivuensis & JR Z 310 & GENT & KR364027 & KR364154 & - & - \\
\hline Lactifluus lamprocystidiatus & EH 72-195 & GENT & KR364015 & - & - & - \\
\hline Lactifluus leae & $\mathrm{FH} 12-013$ & GENT & KF432957 & KR364213 & KR364292 & KR364419 \\
\hline Lactifluus leonardii & GG 07-02-04 & & GU258308 & GU265668 & GU258408 & KR364495 \\
\hline Lactifluus leoninus & DS $07-454$ & GENT & KF220055 & JN388989 & JN375592 & JN389188 \\
\hline Lactifluus leptomerus & AV-KD-KVP 09-131 & GENT & JN388972 & JN389023 & JN375625 & JN389169 \\
\hline Lactifluus lepus & $\begin{array}{l}\mathrm{RC} / \text { Guad 08-042 } \\
\mathrm{RC} / \text { Guad 05-029 }\end{array}$ & $\begin{array}{l}\text { LIP } \\
\text { LIP }\end{array}$ & $\begin{array}{l}\text { KP691414 } \\
\text { MK046811 }\end{array}$ & $\begin{array}{l}\text { KP691423 } \\
\text { MK046774 }\end{array}$ & $\begin{array}{l}\text { KP752179 } \\
-\end{array}$ & - \\
\hline Lactifluus leucophaeus & LTH 182 & GENT & KF220059 & KF220157 & KF220243 & KR364420 \\
\hline Lactifluus longipilus & LTH 184 & GENT & HQ318256 & HQ318169 & HQ328905 & JN389152 \\
\hline Lactifluus luteolus & AV 05-253 & GENT & KR364016 & KR364142 & KJ210067 & KR364440 \\
\hline Lactifluus luteopus & EDC 11-087 & GENT & KR364049 & KR364176 & KR364312 & KR364441 \\
\hline Lactifluus madagascariensis & BB 99-409 & $\mathrm{PC}$ & AY606977 & DQ421975 & DQ421914 & - \\
\hline Lactifluus marmoratus & LD 15-066 & GENT & MK046805 & MK046768 & MK063907 & MK089574 \\
\hline Lactifluus melleus & AV $11-183$ & GENT & KR364060 & KR364189 & KR364277 & KR364389 \\
\hline Lactifluus multiceps & TH 9154A & BRG, DUKE & JN168731 & - & - & - \\
\hline Lactifluus murinipes & $\begin{array}{l}\text { LD 15-018 } \\
\text { LD 15-057 } \\
\text { LD 15-054 } \\
\text { LD 15-015 } \\
\text { LD 15-020 } \\
\text { LD 15-032 } \\
\text { CL/MART06.019 } \\
\text { F.1890 } \\
\text { J.P. Fiard 849A }\end{array}$ & $\begin{array}{l}\text { GENT } \\
\text { GENT } \\
\text { GENT } \\
\text { GENT } \\
\text { GENT } \\
\text { GENT } \\
\text { LIP } \\
\text { LIP } \\
\text { K }\end{array}$ & $\begin{array}{l}\text { MK046814 } \\
\text { MK046815 } \\
\text { MK046828 } \\
\text { MK046832 } \\
\text { MK046836 } \\
\text { MK046838 } \\
\text { KP691417 } \\
\text { KP691418 } \\
\text { MK046855 }\end{array}$ & $\begin{array}{l}- \\
- \\
\text { MK046778 } \\
\text { MK046782 } \\
\text { MK046785 } \\
\text { MK046787 } \\
\text { KP691426 } \\
- \\
-\end{array}$ & $\begin{array}{l}- \\
- \\
\text { MK063911 } \\
\text { MK063915 } \\
\text { MK063918 } \\
\text { MK063920 } \\
- \\
- \\
-\end{array}$ & $\begin{array}{l}- \\
- \\
\text { MK089578 } \\
\text { MK089580 } \\
\text { MK089581 } \\
\text { MK089579 } \\
- \\
- \\
-\end{array}$ \\
\hline Lactifluus nebulosus & $\begin{array}{l}\text { LD 15-059 } \\
\text { LD 15-061 } \\
\text { PAM-Mart12-90 } \\
\text { PAM/Mart 05-091 } \\
\text { J.P. Fiard 828A }\end{array}$ & $\begin{array}{l}\text { GENT } \\
\text { GENT } \\
\text { LIP } \\
\text { LIP } \\
\text { K }\end{array}$ & $\begin{array}{l}\text { MK046804 } \\
\text { MK046833 } \\
\text { KP691415 } \\
\text { MK046850 } \\
\text { MK046856 }\end{array}$ & $\begin{array}{l}\text { MK046766 } \\
\text { MK046783 } \\
\text { KP691424 } \\
\text { MK046799 } \\
-\end{array}$ & $\begin{array}{l}\text { MK063905 } \\
\text { MK063916 } \\
\text { KP691432 } \\
- \\
-\end{array}$ & $\begin{array}{l}\text { MK089572 } \\
\text { MK089573 } \\
\text { KR364396 } \\
- \\
-\end{array}$ \\
\hline Lactifluus neotropicus & R.W.G. Dennis 97 & $\mathrm{~K}$ & MN102680 & - & - & - \\
\hline Lactifluus nonpiscis & AV $11-137$ & GENT & KR364058 & KR364185 & KR364317 & KR364445 \\
\hline Lactifluus ochrogalactus & AV/KD/KVP 09-120 & GENT & KR364130 & KR364248 & KR364318 & KR364446 \\
\hline Lactifluus oedematopus & KVP 12-001 & GENT & KR364100 & KR364232 & KR364319 & KR364447 \\
\hline Lactifluus pallidilamellatus & $\begin{array}{l}\text { Montoya } 4716 \\
\text { AV } 17-012 \\
\text { AV 17-015 }\end{array}$ & $\begin{array}{l}\text { GENT } \\
\text { GENT } \\
\text { GENT }\end{array}$ & $\begin{array}{l}\text { JQ753824 } \\
\text { MN102682 } \\
\text { MN102684 }\end{array}$ & $\begin{array}{l}\text { JQ348268 } \\
- \\
-\end{array}$ & $\begin{array}{l}- \\
- \\
-\end{array}$ & $\begin{array}{l}\text { MN128632 } \\
- \\
-\end{array}$ \\
\hline Lactifluus panuoides & $\begin{array}{l}\text { D.N. Pegler } 3133 \\
\text { RC/Guy10_024 } \\
\text { RC/Mart 03-077 } \\
\text { CL/GUAD06.045 } \\
\text { R.W.G. Dennis 109A }\end{array}$ & $\begin{array}{l}\mathrm{K} \\
\text { LIP } \\
\text { LIP } \\
\text { LIP } \\
\mathrm{K}\end{array}$ & $\begin{array}{l}\text { MK046858 } \\
\text { KJ786647 } \\
\text { MK046807 } \\
\text { MK046843 } \\
\text { MK046859 }\end{array}$ & $\begin{array}{l}- \\
\text { KJ786551 } \\
\text { MK046770 } \\
- \\
-\end{array}$ & $\begin{array}{l}- \\
\text { KP691428 } \\
\text { MK063908 } \\
- \\
-\end{array}$ & $\begin{array}{l}- \\
- \\
\text { MN128627 } \\
- \\
-\end{array}$ \\
\hline Lactifluus pegleri & $\begin{array}{l}\text { LD } 15-042 \\
\text { LD 15-014 } \\
\text { LD 15-049 } \\
\text { PAM-Mart12-91 } \\
\text { PAM/Mart 05-088 } \\
\text { PAM-Mart12-54 } \\
\text { J.P. Fiard 821B }\end{array}$ & $\begin{array}{l}\text { GENT } \\
\text { GENT } \\
\text { GENT } \\
\text { LIP } \\
\text { LIP } \\
\text { LIP } \\
\text { K }\end{array}$ & $\begin{array}{l}\text { MK046831 } \\
\text { MK046835 } \\
\text { MK046837 } \\
\text { KP691416 } \\
\text { MK046808 } \\
\text { MK046809 } \\
\text { MK046860 }\end{array}$ & $\begin{array}{l}\text { MK046781 } \\
\text { MK046784 } \\
\text { MK046786 } \\
\text { KP691425 } \\
\text { MK046771 } \\
\text { MK046772 } \\
-\end{array}$ & $\begin{array}{l}\text { MK063914 } \\
\text { MK063917 } \\
\text { MK063919 } \\
\text { KP691433 } \\
- \\
- \\
-\end{array}$ & $\begin{array}{l}\text { MK089582 } \\
\text { MK089583 } \\
- \\
\text { KR364397 } \\
- \\
- \\
-\end{array}$ \\
\hline Lactifluus pelliculatus & JD 956 & MEISE & KR364080 & KR364209 & KR364321 & KR364449 \\
\hline Lactifluus persicinus & EDC 12-001 & GENT & KR364061 & KR364190 & KR364298 & KR364426 \\
\hline Lactifluus petersenii & AV 05-300 & GENT & GU258281 & GU265642 & GU258382 & KR364450 \\
\hline Lactifluus phlebonemus & EDC 12-023 & GENT & KR364062 & KR364191 & KR364322 & KR364451 \\
\hline Lactifluus phlebophyllus & BB 00-1388 & PC & AY606974 & DQ421979 & DQ421918 & - \\
\hline Lactifluus pilosus & LTH 205 & GENT & KR364006 & KR364134 & KR364323 & KR364452 \\
\hline Lactifluus pinguis & AV-RW 04-023=LTH117 & GENT & HQ318211 & HG318111 & HQ328858 & JN389126 \\
\hline Lactifluus piperatus & 2001081968 & GENT & KF220119 & KF241840 & KF241842 & KR364453 \\
\hline Lactifluus pulchellus & KW 304/FH 12-037 & GENT & KR364092 & KR364223 & KR364306 & KR364434 \\
\hline Lactifluus pumilus & EDC 12-066 & GENT & KR364067 & KR364196 & KR364332 & KR364462 \\
\hline Lactifluus putidus & $\begin{array}{l}\text { LD } 15-006 \\
\text { LD 15-017 } \\
\text { LD 15-002 } \\
\text { LD 15-040 } \\
\text { LD 15-041 } \\
\text { LD 15-065 } \\
\text { LD 15-011 } \\
\text { LD 15-033 } \\
\text { LD 15-034 } \\
\text { LD 15-062 } \\
\text { LD 15-004 } \\
\text { LD 15-039 } \\
\text { LD 15-030 } \\
\text { PAM/Mart 11-013 } \\
\text { PAM-Mart12-88 } \\
\text { RC/Mart 05-110 }\end{array}$ & $\begin{array}{l}\text { GENT } \\
\text { GENT } \\
\text { GENT } \\
\text { GENT } \\
\text { GENT } \\
\text { GENT } \\
\text { GENT } \\
\text { GENT } \\
\text { GENT } \\
\text { GENT } \\
\text { GENT } \\
\text { GENT } \\
\text { GENT } \\
\text { LIP } \\
\text { LIP } \\
\text { LIP }\end{array}$ & $\begin{array}{l}\text { MK046818 } \\
\text { MK046819 } \\
\text { MK046820 } \\
\text { MK046821 } \\
\text { MK046822 } \\
\text { MK046823 } \\
\text { MK046824 } \\
\text { MK046825 } \\
\text { MK046826 } \\
\text { MK046827 } \\
\text { MK046829 } \\
\text { MK046830 } \\
\text { MK046834 } \\
\text { KP691413 } \\
\text { MK046806 } \\
\text { MK046810 }\end{array}$ & $\begin{array}{l}- \\
- \\
- \\
- \\
- \\
- \\
- \\
- \\
\text { MK046777 } \\
\text { MK046779 } \\
\text { MK046780 } \\
- \\
\text { KP691422 } \\
\text { MK046769 } \\
\text { MK046773 }\end{array}$ & $\begin{array}{l}- \\
- \\
- \\
- \\
- \\
- \\
- \\
- \\
\text { MK063910 } \\
- \\
\text { MK063912 } \\
\text { MK063913 } \\
- \\
\text { KP691431 } \\
- \\
-\end{array}$ & $\begin{array}{l}- \\
- \\
- \\
- \\
- \\
- \\
- \\
- \\
\text { MK089575 } \\
- \\
\text { MK089577 } \\
\text { MK089576 } \\
- \\
- \\
- \\
-\end{array}$ \\
\hline
\end{tabular}


Table 1 (cont.)

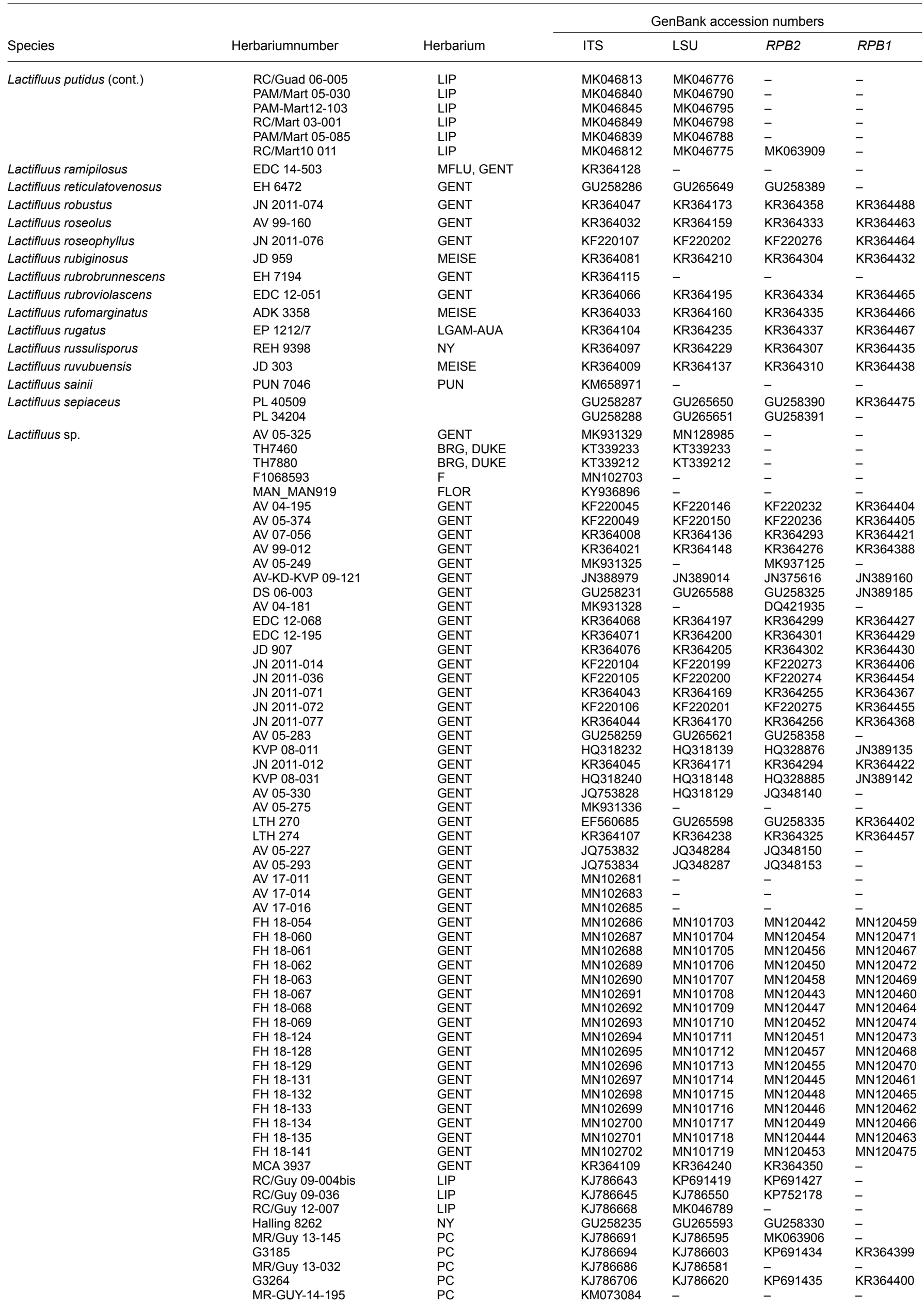


Table 1 (cont.)

\begin{tabular}{|c|c|c|c|c|c|c|}
\hline \multirow[b]{2}{*}{ Species } & \multirow[b]{2}{*}{ Herbariumnumber } & \multirow[b]{2}{*}{ Herbarium } & \multicolumn{4}{|c|}{ GenBank accession numbers } \\
\hline & & & ITS & LSU & $R P B 2$ & $R P B 1$ \\
\hline Lactifluus sp. (cont.) & $\begin{array}{l}\text { G4727 } \\
\text { G4836 } \\
\text { G4797 } \\
\text { JLC } 060310-01 \\
\text { TENN } 064342 \\
\text { TENN } 065854 \\
\text { TENN } 065929 \\
\text { LM4640 } \\
\text { LM-UNAH } 0072 \\
\text { LM-UNAH 0073 } \\
\text { PGK13-130 } \\
\text { ASM 12,075 }\end{array}$ & $\begin{array}{l}\text { TENN } \\
\text { TENN } \\
\text { TENN } \\
\text { XAL } \\
\text { XAL } \\
\text { XAL }\end{array}$ & $\begin{array}{l}\text { KM073087 } \\
\text { KM073083 } \\
\text { KM073085 } \\
\text { KJ786714 } \\
\text { KR364103 } \\
\text { KR364101 } \\
\text { KR364102 } \\
\text { HQ168369 } \\
\text { HM639277 } \\
\text { HM639278 } \\
\text { KP691436 } \\
\text { MN102679 }\end{array}$ & $\begin{array}{l}- \\
- \\
- \\
- \\
\text { KR364234 } \\
\text { MN128986 } \\
\text { KR364233 } \\
- \\
- \\
- \\
\text { KR605507 } \\
-\end{array}$ & $\begin{array}{l}- \\
- \\
- \\
- \\
\text { KR364324 } \\
\text { KR364271 } \\
\text { KR364308 } \\
- \\
- \\
- \\
- \\
-\end{array}$ & $\begin{array}{l}- \\
- \\
- \\
- \\
\text { KR364456 } \\
\text { KR364383 } \\
\text { KR364436 } \\
- \\
- \\
- \\
- \\
-\end{array}$ \\
\hline Lactifluus subclarkeae & REH 9231 & NY & KR364095 & KR364227 & KR364346 & KR364477 \\
\hline Lactifluus subgerardii & AV 05-269 & GENT & GU258263 & GU265625 & GU258362 & KR364478 \\
\hline Lactifluus subiculatus & SLM 10114 & BRG, RMS & JQ405654 & - & - & - \\
\hline Lactifluus subkigomaensis & EDC 11-159 & GENT & KR364050 & KR364177 & KR364295 & KR364423 \\
\hline Lactifluus subpruinosus & JN 2011-061 & GENT & KR364046 & KR364172 & KR364357 & KR364487 \\
\hline Lactifluus subvellereus & AV 05-210 & GENT & KR364010 & KR364138 & KR364347 & KR364479 \\
\hline Lactifluus subvolemus & KVP 08-048 & GENT & JQ753927 & - & KR364356 & KR364486 \\
\hline Lactifluus sudanicus & AV $11-174$ & GENT & HG426469 & KR364186 & KR364348 & KR364480 \\
\hline Lactifluus tanzanicus & AV 11-017 & GENT & KR364053 & KR364180 & KR364296 & KR364424 \\
\hline Lactifluus tenuicystidiatus & JN 2011-080 & GENT & KR364048 & KR364174 & KR364359 & KR364489 \\
\hline Lactifluus uapacae & AV 07-048 & GENT & KR364007 & KR364135 & KR364352 & KR364483 \\
\hline Lactifluus urens & EDC 14-032 & GENT & KR364124 & KR364247 & KR364353 & - \\
\hline Lactifluus vellereus & ATHU-M 8077 & ATHU-M & KR364106 & KR364237 & KR364354 & KR364484 \\
\hline Lactifluus velutissimus & JD 886 & MEISE & KR364075 & KR364204 & KR364355 & KR364485 \\
\hline Lactifluus venezuelanus & $\begin{array}{l}\text { RC/Mart 03-120 } \\
\text { RC/Guad 03-048 } \\
\text { RC/Guad11-017 } \\
\text { PAM/Guad 10-036 } \\
\text { PAM/Guad 10-037 } \\
\text { F.1980 }\end{array}$ & $\begin{array}{l}\text { LIP } \\
\text { LIP } \\
\text { LIP } \\
\text { LIP } \\
\text { LIP }\end{array}$ & $\begin{array}{l}\text { MK046842 } \\
\text { MK046847 } \\
\text { KP691411 } \\
\text { MK046844 } \\
\text { MK046846 } \\
\text { MK046848 }\end{array}$ & $\begin{array}{l}\text { MK046792 } \\
\text { MK046797 } \\
\text { KP691420 } \\
\text { MK046794 } \\
\text { MK046796 } \\
-\end{array}$ & $\begin{array}{l}- \\
- \\
\text { KP691429 } \\
\text { MK063922 } \\
\text { MK063923 } \\
-\end{array}$ & $\begin{array}{l}- \\
- \\
- \\
\text { MN128630 } \\
\text { MN128631 } \\
-\end{array}$ \\
\hline Lactifluus veraecrucis & M 8025 & ENCB & KR364112 & KR364241 & - & - \\
\hline Lactifluus versiformis & AV-KD-KVP 09-045 & GENT & JN388967 & JN389031 & JN375632 & JN389177 \\
\hline Lactifluus vitellinus & KVP 08-024 & GENT & HQ318236 & HQ318144 & HQ328881 & JN389138 \\
\hline Lactifluus volemoides & TS 0705 & GENT & KR364038 & KR364165 & - & - \\
\hline Lactifluus volemus & $\begin{array}{l}\text { KVP 11-002 } \\
\text { REH } 9320\end{array}$ & $\begin{array}{l}\text { GENT } \\
\text { NY }\end{array}$ & $\begin{array}{l}\text { JQ753948 } \\
\text { KR364096 }\end{array}$ & $\begin{array}{l}\text { KR364175 } \\
\text { KR364228 }\end{array}$ & $\begin{array}{l}\text { KR364360 } \\
\text { KR364362 }\end{array}$ & $\begin{array}{l}\text { KR364490 } \\
\text { KR364492 }\end{array}$ \\
\hline Lactifluus wirrabara & GG 24-01-04 & & GU258307 & GU265667 & GU258407 & KR364494 \\
\hline Lactifluus xerampelinus & MH 201176 & GENT & KR364099 & KR364231 & KR364364 & KR364496 \\
\hline
\end{tabular}

2. a part of the ribosomal large subunit $28 \mathrm{~S}$ region (LSU), using primers LROR and LR5 (Moncalvo et al. 2000);

3. the region between the conserved domains 6 and 7 of the second largest subunit of the RNA polymerase II (RPB2), using primers bRPB2-6F and fRPB2-7cR (Liu et al. 1999, Matheny 2005); and

4. the region between domains $A$ and $C$ of nuclear gene encoding the largest subunit of RNA polymerase II (RPB1), using primers RPB1-Ac and RPB1-Cr (Stiller \& Hall 1997, Matheny et al. 2002).

PCR products were sequenced using an automated $A B I 3730$ $X \mathrm{~L}$ capillary sequencer (Life Technology) at Macrogen. Forward and reverse sequences were assembled into contigs and edited with Sequencher v. 5.0 (Gene Codes Corporation, Ann Arbor, MI, USA) or BioloMICS (BioAware SA NV). The dataset was supplemented with closely related sequences from GenBank and worldwide reference sequences from De Crop et al. (2017) (Table 1). Sequences were aligned online in the multiple sequence alignment program MAFFT v. 7 (Katoh \& Toh 2008), using the E-INS-I strategy. Trailing ends were trimmed and the alignment was manually edited where needed in Mega 6 (Tamura et al. 2013). The alignment is deposited in TreeBASE (Submission ID 24693). First, the ITS+LSU alignment was partitioned into partial 18S, ITS1, 5.8S, ITS2 and partial $28 \mathrm{~S}$. Both $R P B 1$ and $R P B 2$ alignments were partitioned into the intron(s) and the first, second and third codon positions of the exon. PartitionFinder was used to find the appropriate partitioning scheme (Lanfear et al. 2017). Maximum likelihood (ML) analyses, using RAxML v. 8.0.24 (Stamatakis 2014), were combined with the Rapid Bootstrapping algorithm with 1000 replicates under the GTRCAT option (Stamatakis et al. 2008). There was no supported conflict between the separate gene trees, so they were concatenated. ML analyses were conducted on the CIPRES Science Gateway (Miller et al. 2010).

\section{Distribution of closest relative(s)}

To investigate whether species occurring in Central America and the Caribbean are more closely related to North or to South American species, the following steps were undertaken. For each largest possible clade consisting only of species occurring in Central America and/or the Caribbean (i.e., a total of 22 clades), the closest relative(s) was/were determined by considering the closest node with a bootstrap support value of at least 70 . If there was only one most closely related clade, or if those most closely related clades originated from the same continent, a value of one was added towards the count for that continent. If the closest relatives of a clade were originating from multiple continents, a value of one was added for each of these continents. For each Central American or Caribbean clade, hosts and altitude were noted when possible, and counts of the closest relatives of different plant families and altitudes were performed in the same way. These counts were visualised in a bar plot using $\mathrm{R}$ (R Core Team 2018). 


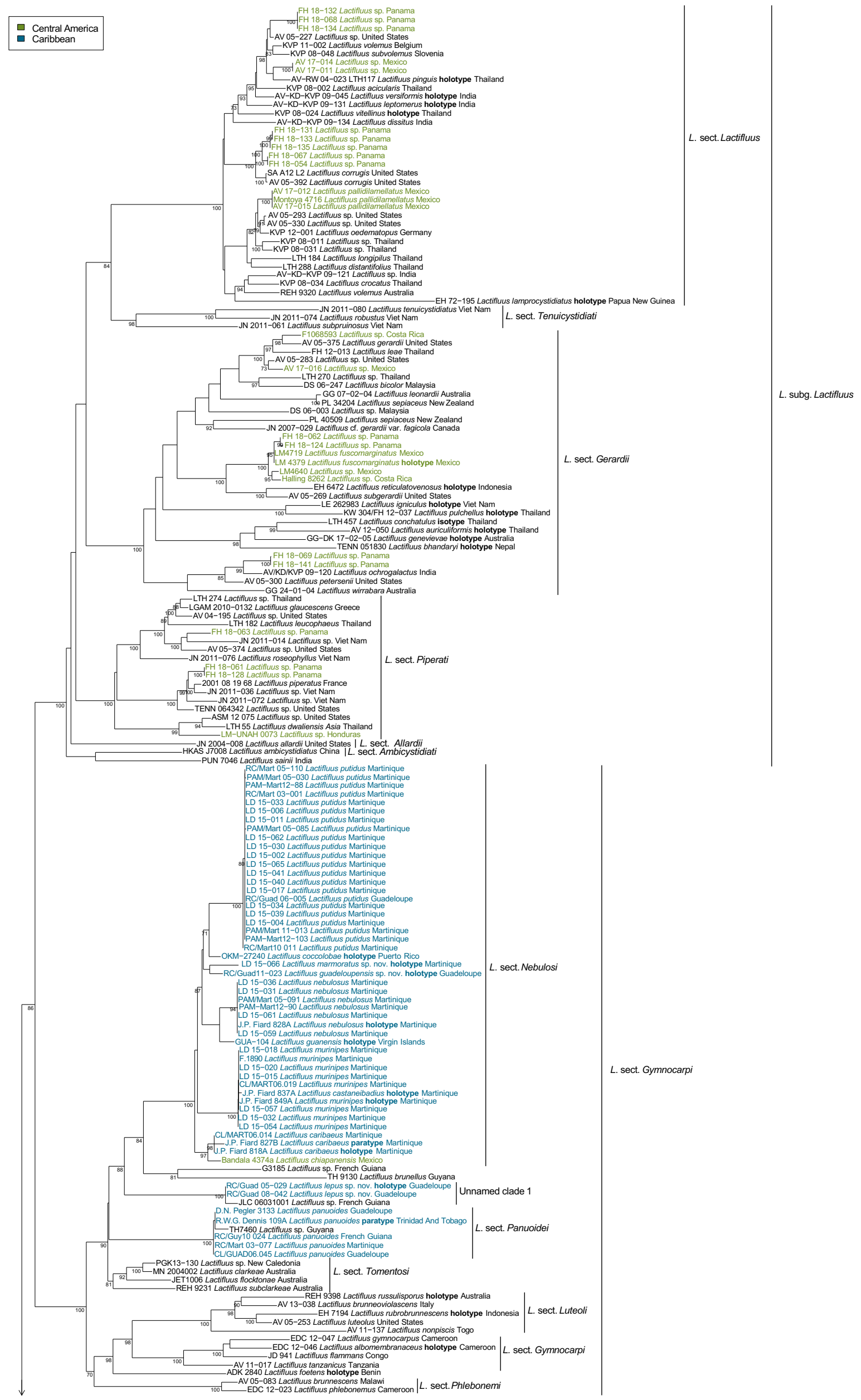

Fig. 1 Maximum Likelihood tree based on concatenated ITS, LSU, RPB2 and RPB1 sequence data. Maximum Likelihood bootstrap values > 70 are shown. 


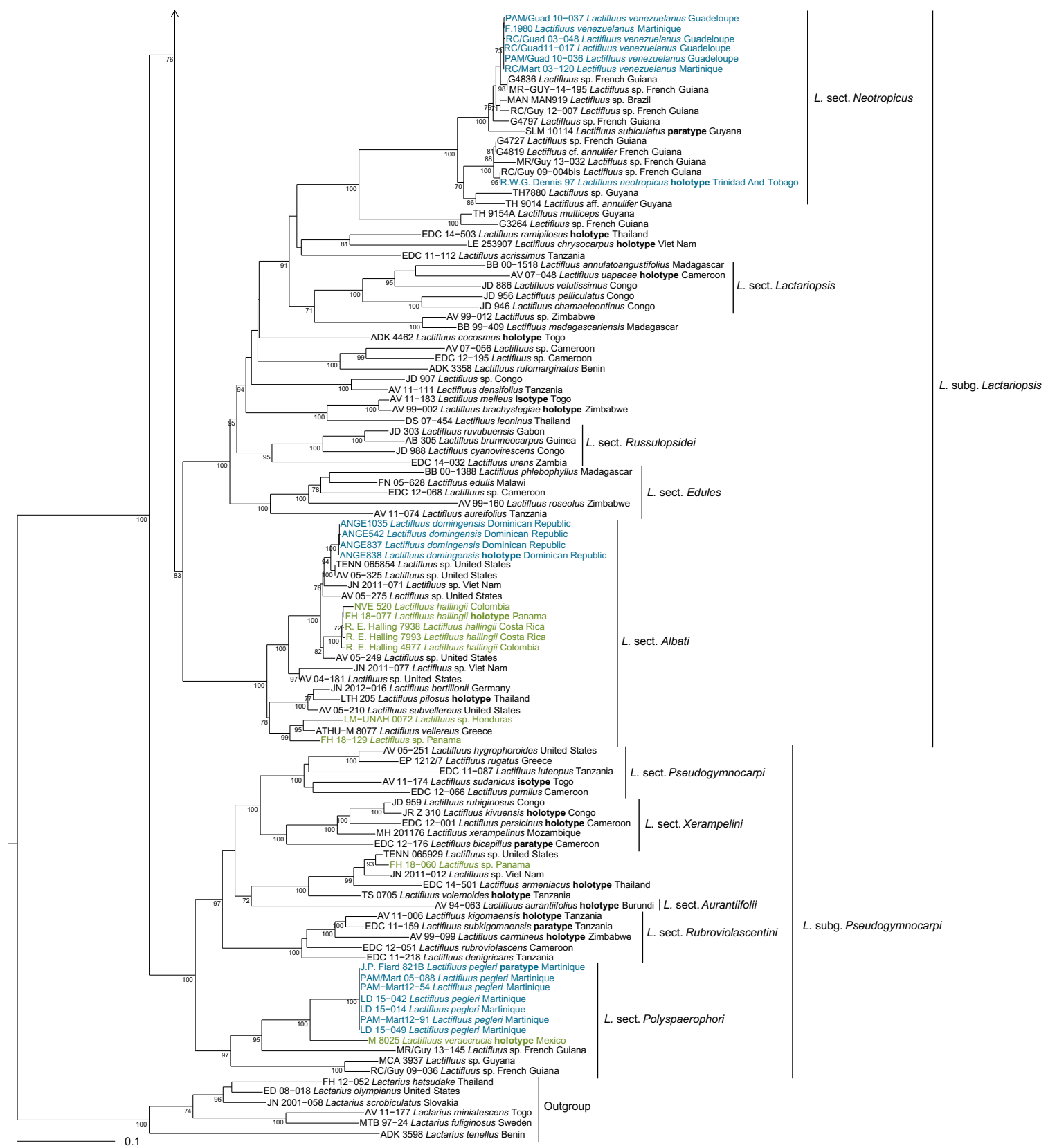

Fig. 1 (cont.)

\section{RESULTS}

\section{Taxonomy}

\section{Lactifluus subg. Lactifluus}

\section{Lactifluus sect. Lactifluus}

Lactifluus pallidilamellatus (Montoya \& Bandala) Van de Putte, Mycotaxon 120: 444. 2012

三 Lactarius pallidilamellatus Montoya \& Bandala, Cryptog. Mycol. 25 (1): 16. 2004.

Ecology - Found in mesophytic (subtropical) forest, with Carpinus caroliniana.

Distribution - Known from Veracruz, Mexico.

Notes - Lactifluus pallidilamellatus is characterised by its slender habit, orange pileus and stipe, crowded, cream to yellowish lamellae, brown discolouring context, copious white latex, prominent lamprocystidia, basidiospores measuring $(6.4-) 7.2-8.8 \times(5.6-) 6.4-7.5(-8) \mu \mathrm{m}$, with a heavy reticulum and relatively short terminal elements in the pileipellis, measuring 16-40.8 × 2.4-12.8 $\mu \mathrm{m}$ (Montoya \& Bandala 2004). The most closely related described species is $L$. oedematopus from Europe (Fig. 1), which is morphologically very similar, and has also been reported from forests with Carpinus (Van de Putte et al. 2016), but their different distribution easily distinguishes them from each other.

No other species in L. sect. Lactifluus have been described from Central America, nor the Caribbean or South America. However, our phylogeny reveals four undescribed species from this area in this section, three from Panama and one from Mexico (Fig. 1). Since this section represents a difficult species complex (Van de Putte 2012), in which morphological differences are often very subtle, a detailed study on this complex will be needed to further unravel these species. 
Lactifluus sect. Gerardii (A.H. Sm. \& Hesler) Stubbe, Persoonia 38: 76. 2016

Lactifluus fuscomarginatus (Montoya, Bandala \& I. Haug) Delgat, comb. nov. — MycoBank MB831635

$\equiv$ Lactarius fuscomarginatus Montoya, Bandala \& I. Haug, Mycologia 104 (1): 176. 2012.

Ecology - Found in Fagus grandifolia var. mexicana forest. Distribution - Known from Veracruz, Mexico.

Notes - Lactifluus fuscomarginatus is characterised by the dark pileus and stipe, whitish lamellae with blackish brown lamellae edges, pigmented, projecting and subcylindrical cheiloleptocystidia and basidiospores measuring (8-)9-10-10.2-11 $\times(7-) 8-9-9.2-10.5(-11) \mu \mathrm{m}(\mathrm{Q}=1.08-1.14)$, with reticulate ornamentation, with rounded to somewhat sharp ridges up to $0.5 \mu \mathrm{m}$ high. Lactifluus fuscomarginatus is situated in a clade together with three undescribed species from Mexico and Central America, and the closest described relatives to this clade are $L$. reticulatovenosus from Indonesia and $L$. subgerardii from North America (Fig. 1). Lactifluus fuscomarginatus thus belongs to L. sect. Gerardii (Fig. 1), and not to Lactarius subg. Plinthogalus, and is here combined in Lactifluus.

\section{Lactifluus subg. Gymnocarpi (R. Heim ex Verbeken)}

De Crop, Persoonia 38: 75. 2016
Lactifluus sect. Nebulosi Delgat, sect. nov. - MycoBank MB828339

Typus. Lactarius nebulosus Pegler, Kew Bull. 33: 610. 1979 (三 Lactifluus nebulosus (Pegler) De Crop).

Pileus medium to large sized, firm, convex with central depression to infundibuliform, with inflexed margin when young; surface slightly velutinous, often slightly wrinkled, sometimes smooth, irregular or strongly wrinkled, white-grey with brown spots to brown. Stipe central, cylindrical to tapering downwards, firm to stuffed, whitish, staining brown. Lamellae subdecurrent to deeply decurrent, often rather distant, white to cream; edge concolourous. Context white, in most cases turning brown. Odour in most cases unpleasant, fishy. Latex watery white, in most cases staining brown and taste mild, in the case of L. murinipes unchanging and acrid.

Basidiospores subglobose to ellipsoid; ornamentation composed of isolated, rounded warts up to $1 \mu \mathrm{m}$ high. True pleuromacrocystidia present in most species, up to $140-185 \mu \mathrm{m}$ long, cylindrical to subfusiform with rounded, mucronate, rostrate or slightly moniliform apex. Pileipellis a trichoderm to palisade; terminal elements in most cases thin-walled.

Notes - Lactifluus sect. Nebulosi corresponds to clade 9 in De Crop et al. (2017) and belongs in L. subg. Gymnocarpi. In contrast to the other described sections in this subgenus that completely lack true pleurocystidia, most species of $L$. sect. Nebulosi have conspicuous pleuromacrocystidia. The section contains only Neotropical collections and is characterised by dull fruiting body colours (a brown-grey pileus and a white-grey
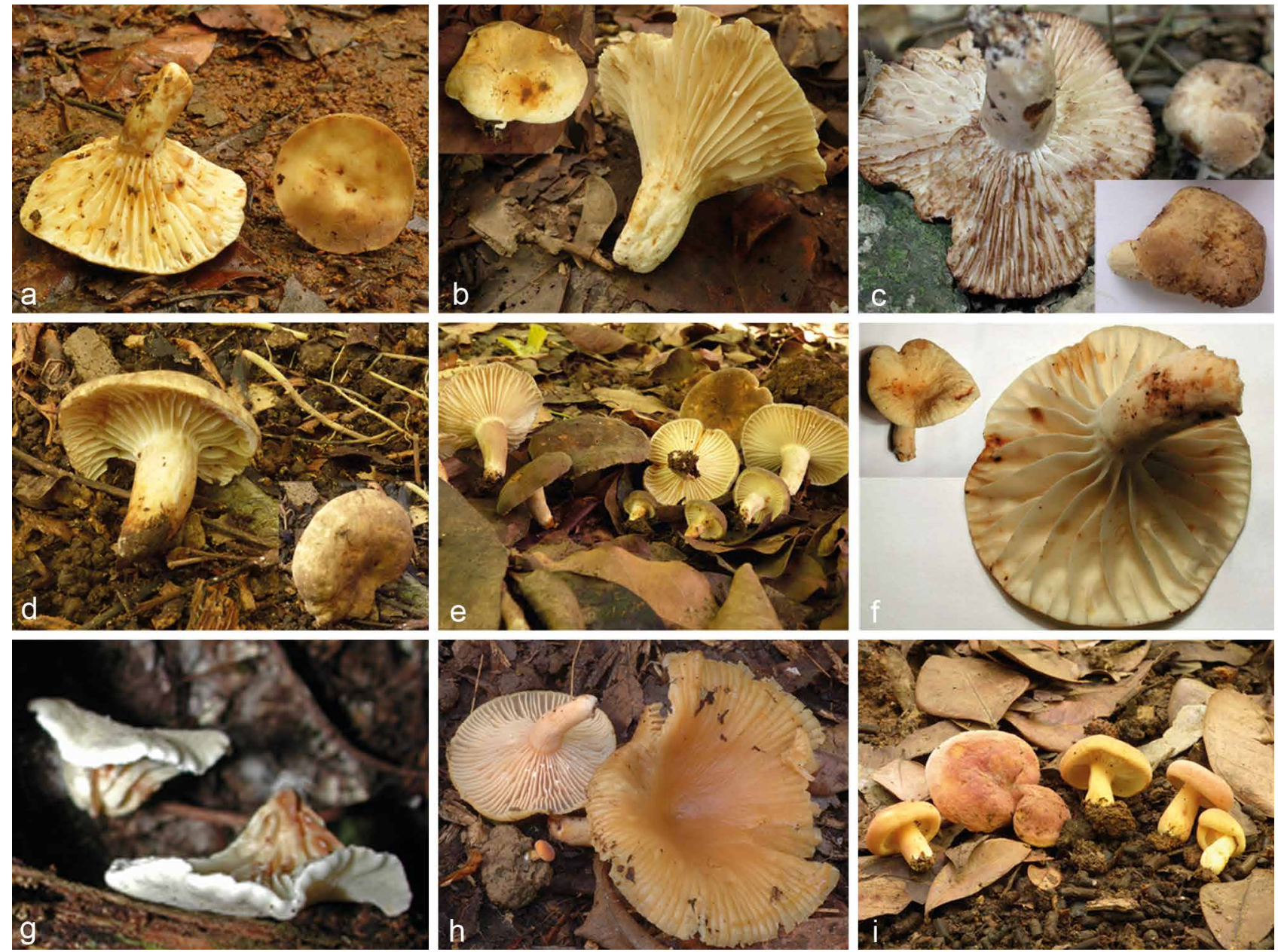

Fig. 2 Basidiocarps. a. Lactifluus putidus, LD 15-002 (L. Delgat); b. Lactifluus nebulosus, LD 15-061, inset LD 15-059 (L. Delgat); c. Lactifluus guadeloupensis, RC/Guad11-023 (R. Courtecuisse); d. Lactifluus marmoratus, LD 15-066 (L. Delgat); e. Lactifluus murinipes, LD 15-020 (L. Delgat); f. Lactifluus lepus, RC/ Guad 05-029 (R. Courtecuisse); g. Lactifluus panuoides, RC/Mart 03-077 (R. Courtecuisse); h. Lactifluus venezuelanus, PAM/Guad 10-036 (P.-A. Moreau); i. Lactifluus pegleri, LD 15-014 (L. Delgat). 
stipe), an unpleasant fishy odour in all species except $L$. murinipes, and broadly ellipsoid spores with isolated, rounded warts up to $1 \mu \mathrm{m}$ high.

Lactifluus putidus (Pegler) Verbeken, Mycotaxon 120: 446, 2012 - Fig. 2a, 3

三Lactarius putidus Pegler, Kew Bull. 33 (4): 620. 1979.

Pileus 14-66 mm diam, plano-convex with central depression and inflexed margin when young, infundibuliform with straight to deflexed margin when adult; surface somewhat to very wrinkled, brown $(6 \mathrm{E} 3-4,6 \mathrm{~F} 3-5)$ with yellowish light brown areas, often in the centre (4A3-5). Stipe $8-30 \times 4-14 \mathrm{~mm}$, cylindrical, white to yellowish white (4A1-4), with brown stains (5D5, 6E3-5). Lamellae decurrent, medium spaced to distant, sometimes slightly intervenose, white to cream (4A2-3), staining brown (6E5, 6F4-7); edge entire and concolourous. Context white, firm, turning dark brown, often first turning violaceous brown, dark green blue with guaiac, greyish blue-green with $\mathrm{FeSO}_{4}$. Odour very unpleasant, like rotten fish or urine. Taste mild. Latex very abundant, watery white, staining brown, mild.

Basidiospores broadly ellipsoid to ellipsoid, 6.5-7.7-9.3-10.6 $\times 5.3-6.2-6.9-7.7 \mu \mathrm{m}(\mathrm{Q}=1.04-1.23-1.36-1.53)$; ornamentation amyloid, composed of isolated rounded warts up to $1 \mu \mathrm{m}$ high, rarely connected by fine connective lines; plage inamyloid. Basidia 51-67.5-84.5(-88) ×9-11-13.5 $\mu \mathrm{m}$, subclavate, 4-spored. Pleuromacrocystidia 72.5-121.5-170.5 $\times 5.5-8-10.5 \mu \mathrm{m}$, cylindrical to subfusiform with rounded, mucronate or tapering apex, rarely branching, thin-walled. Pleuropseudocystidia scarce, $4 \mu \mathrm{m}$ diam, not or slightly emergent. Lamellar edge fertile. Hymenophoral trama mixed, with hyphae,

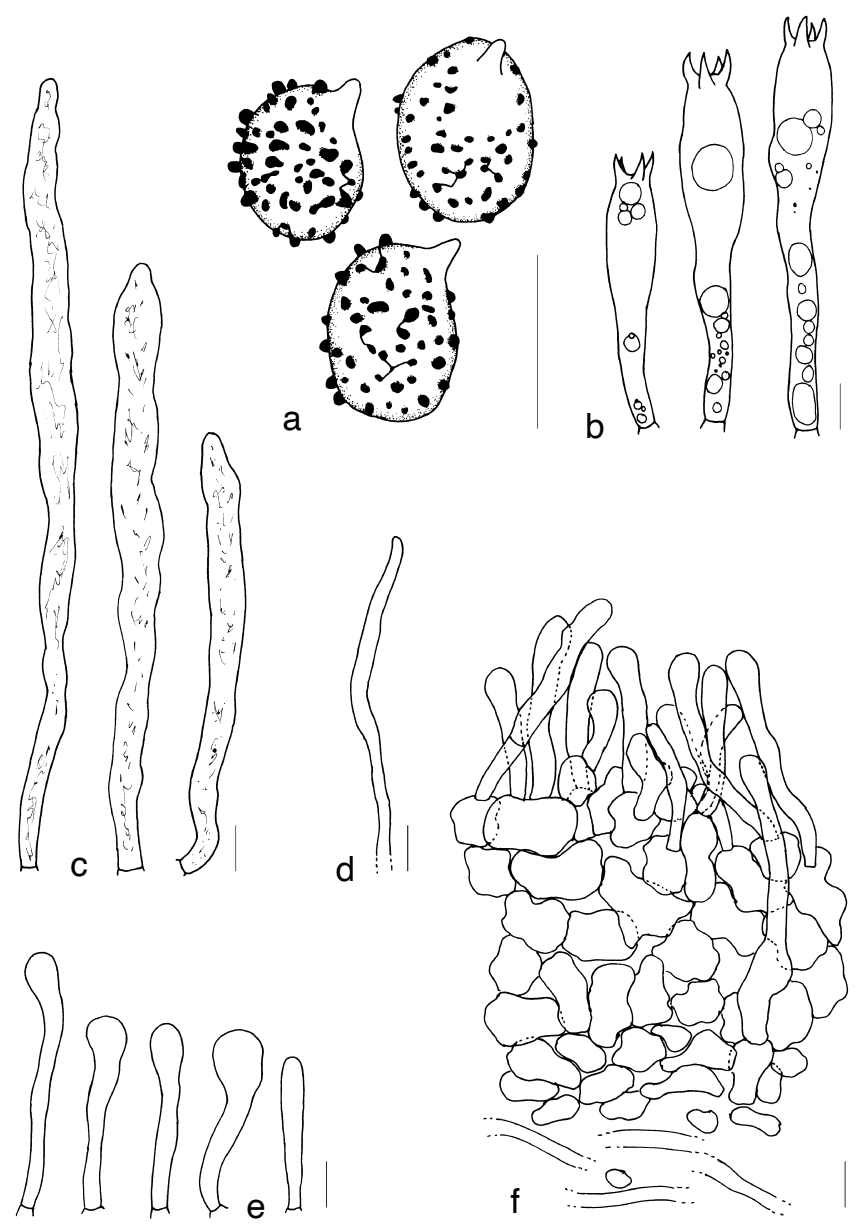

Fig. 3 Lactifluus putidus (LD 15-004, LD 15-011, LD 15-030, LD15-065). a. Basidiospores; b. basidia; c. macrocystidia; d. pseudocystidium; e. pileipellis terminal elements; f. section through the pileipellis. - Scale bars $=10 \mu \mathrm{m}$. lactifers and sphaerocytes. Pileipellis a palisade; elements of the suprapellis $29-41.5-53.5(-55) \times 2.5-3.5-4 \mu \mathrm{m}$, cylindrical to capitate up to $10.5 \mu \mathrm{m}$; subpellis composed of isodiametric cells. Stipitipellis resembling pileipellis.

Ecology - Found in xerophytic and mesophytic forests, with Bursera simaruba, Coccoloba diversifolia, Coccoloba pubescens, Coccoloba swartzii, Guapira fragrans, Inga laurina, Lonchocarpus roseus and Pisonia subcordata.

Distribution - Known from the islands of Martinique and Guadeloupe.

Specimens examined. MARTINIQUE, Réserve naturelle La Caravelle, Commune de Trinité, Bois de Pointe rouge, soil with Guapira fragrans, Coccoloba pubescens, 03 Nov. 2015, Lynn Delgat, LD 15-004 (GENT); ibid., soil with Guapira fragrans, Coccoloba pubescens, Coccoloba swarzii, 03 Nov. 2015, Lynn Delgat, LD 15-011 (GENT); Réserve naturelle La Caravelle, Trinité, Tartane, vicinity of ruins of Chateau Dubuc $\left(14.769397^{\circ},-60.889991^{\circ}\right.$, alt. $30.7 \mathrm{~m}$ ), soil with Guapira fragrans, Coccoloba swartzii, 08 Nov. 2015, Lynn Delgat, LD 15-030 (GENT); Réserve naturelle La Caravelle, Commune de Trinité, Bois de Pointe rouge $\left(14.757943^{\circ},-60.932939^{\circ}\right.$, alt. $\left.47.8 \mathrm{~m}\right)$, soil with Coccoloba pubescens, Guapira fragrans, 10 Nov. 2015, Lynn Delgat, LD 15-039 (GENT); Commune du Prêcheur, Anse Lévrier (14.844459², $-61.218130^{\circ}$, alt. $\left.64.1 \mathrm{~m}\right)$, soil with Guapira fragrans, 14 Nov. 2015 , Lynn Delgat, LD 15-062 (GENT); ibid., (14.844562 ${ }^{\circ},-61.217664^{\circ}$, alt. $\left.78.3 \mathrm{~m}\right)$, soil with Guapira fragrans, 14 Nov. 2015, Lynn Delgat, LD 15-065 (GENT).

Notes - Lactifluus putidus is a commonly encountered species and is probably the most frequent Lactifluus species in the area (numerous specimens from various collectors have been accumulated through the years and are mainly deposited in $\mathrm{K}$ and LIP). It can easily be recognised in the field by the strongly wrinkled cap in mature specimens, the strong, unpleasant odour and the very abundant latex. When the fruiting body is cut, the latex often first turns violaceous brown before turning dark brown. Microscopically, the presence of capitate terminal elements in the pileipellis and stipitipellis is a distinctive character, which was not observed in any of the other species from the Antilles. Molecularly, L. putidus is closely related to L. coccolobae (Fig. 1), but can be distinguished from it by the strongly wrinkled pileus, the capitate elements in the pileipellis and the absence of gelatinised hyphae in the pileipellis, in addition to $L$. coccolobae being associated with Coccoloba uvifera in dune habitats in the Greater Antilles.

Lactifluus coccolobae (O.K. Mill. \& Lodge) Delgat, comb. nov. - MycoBank MB828348

इ Lactarius coccolobae O.K. Mill. \& Lodge, Mycologia 92 (3): 564. 2000. fera.

Ecology - Found in sand on dunes under Coccoloba uvi-

Distribution - Known from Puerto Rico and Guana Island, British Virgin Isles.

Notes - Based on the original description this species fits morphologically in L. sect. Nebulosi, notably because of the dull basidiocarp colours, the brown staining of the latex and context, the strong fishy odour and the spore ornamentation with isolated warts (Miller et al. 2000). The placement in this section is confirmed molecularly by the position of the type sequence in the phylogeny (Fig. 1). A similar species is L. guanensis, which also occurs in the Greater Antilles with Coccoloba uvifera, but $L$. coccolobae can be distinguished from this species by its narrower basidia (8-9.5 $\mu \mathrm{m}$ wide), slightly shorter spores (7.2-9(-10.8) $\mu \mathrm{m}$ long), lower spore ornamentation (up to 0.3 $\mu \mathrm{m})$ and a gelatinised pileipellis (Miller et al. 2000). Lactifluus coccolobae is closely related to the Lesser Antillean L. putidus (Fig. 1), but can easily be distinguished from it by the absence of a strongly wrinkled pileus, the absence of capitate elements in the pileipellis and the presence of gelatinised hyphae in the pileipellis. 
Lactifluus guadeloupensis Delgat \& Courtec., sp. nov. MycoBank MB828343; Fig. 2c, 4

Diagnosis: Differs from L. nebulosus and L. marmoratus by the irregular pileus surface, the pruinose lamellae and the presence of many 2-spored basidia.

Typus. Guadeloupe, Grande-Terre, Commune de Saint François, Baie Olive (16.249905 ${ }^{\circ},-61.283412^{\circ}$, alt. $\left.2.9 \mathrm{~m}\right)$, with Guapira and Fabaceae, 06 Aug. 2011, R. Courtecuisse, RC/Guad11-023 (LIP).

\section{Etymology. Refers to the island where the species was found.}

Pileus up to $40 \mathrm{~mm}$ diam, convex with slight central depression; young basidiocarps sometimes umbilicate; surface irregularly bumpy, finely pubescent to velvety, marmorate greyish brown mixed with yellowish to yellowish ochraceous, becoming dull rusty brown. Stipe $20 \times 6-10 \mathrm{~mm}$, short, slightly tapering downwards; surface pruinose, with rather variable colours, dirty cream when young to yellowish brown or marmorate when adult. Lamellae adnate to subdecurrent, distant, thick, more or less intervenose through irregular ridges or bumps, pruinose, yellowish cream, turning rusty brownish. Context cream, turning brown, slightly stuffed. Odour unpleasant, reminding of fish or rotting material, then becoming a more classical lactarioid odour while drying or reminding the odour of $L$. volemus (i.e., agreeable shellfish-like, Jerusalem artichokes). Taste not observed. Latex watery white, colour change and taste not observed. Basidiospores mostly broadly ellipsoid, some subglobose or ellipsoid; size very variable, 7.1-9.4-9.6-11.8(-11.9) × 5.87.5-7.9-9.4(-9.5) $(\mathrm{Q}=1.08-1.23-1.26-1.41)$; ornamentation amyloid, composed of rounded warts, up to $1 \mu \mathrm{m}$ high, isolated; plage inamyloid. Basidia (54-)56.5-75.5-94.5 × 8-10.5$13(-14) \mu \mathrm{m}$, cylindrical to subclavate, majority 4-spored but many 2-spored and some 1- and 3-spored, sometimes with

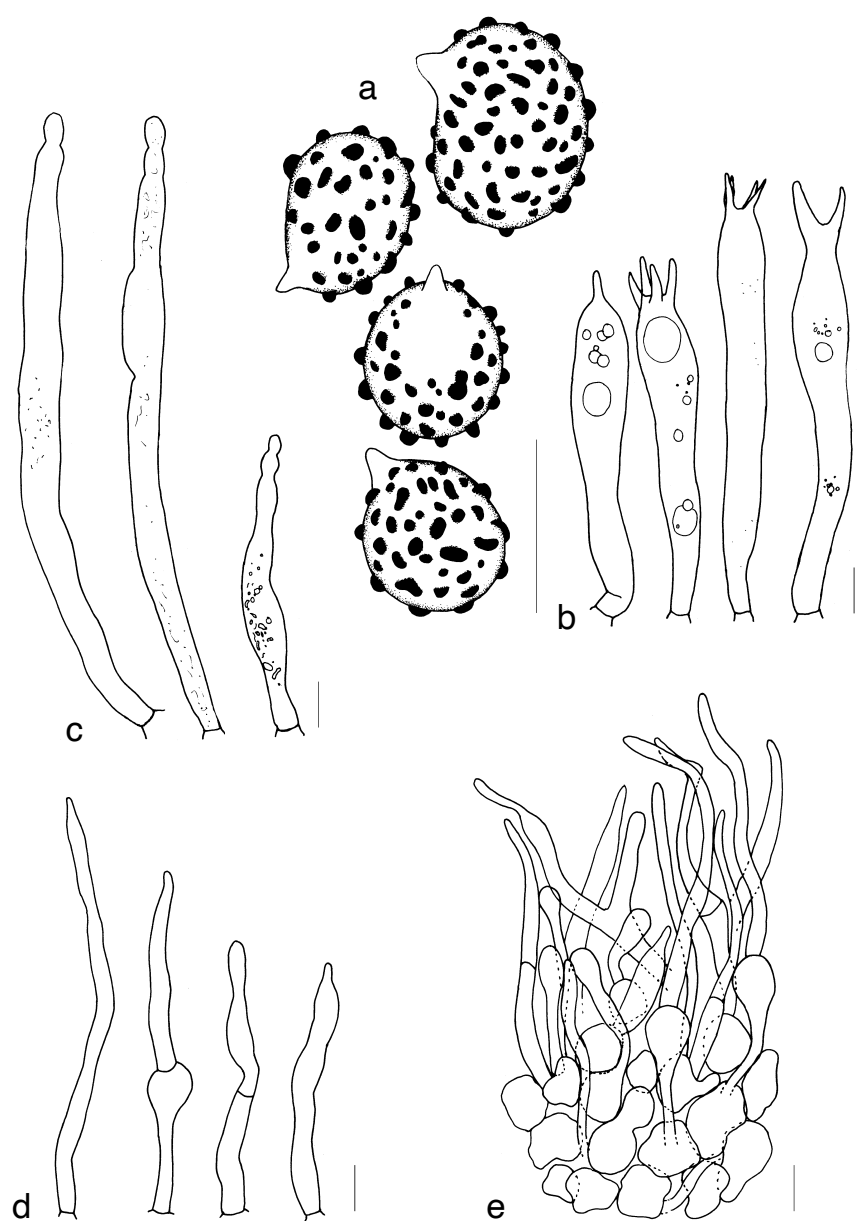

Fig. 4 Lactifluus guadeloupensis (RC/Guad11-023). a. Basidiospores; b. basidia; c. macrocystidia; d. pileipellis terminal elements; e. section through the pileipellis. - Scale bars $=10 \mu \mathrm{m}$. wall locally thickened. Pleuromacrocystidia 53-104.5-155.5 $\times 6.5-8-10 \mu \mathrm{m}$, abundant, cylindrical with moniliform apex, thin-walled. Pleuropseudocystidia absent. Lamellar edge fertile. Hymenophoral trama mixed, with hyphae, lactifers and sphaerocytes. Pileipellis a palisade to trichopalisade; elements of the suprapellis $29-60-91.5 \times 2.5-4.5-6 \mu \mathrm{m}$, cylindrical, some septate, some branching; subpellis composed of isodiametric cells and more elongated cells. Stipitipellis resembling pileipellis, terminal elements slightly shorter, 29.5-42.5-56 × 3-56.5(-7) $\mu \mathrm{m}$.

Ecology - Found in xerophytic forests with Guapira and Fabaceae.

Distribution - Only known from type locality.

Notes - Lactifluus guadeloupensis is morphologically similar to L. nebulosus and L. marmoratus. However, it can be macroscopically distinguished from these two species by an irregular pileus surface and pruinose lamellae. Microscopically it can be distinguished from $L$. nebulosus by longer basidia, longer terminal elements in the pileipellis and potentially by the presence of many 2-spored and some 1- and 3-spored basidia. For microscopic differences with $L$. marmoratus, see the notes on that species. The relationships of $L$. guadeloupensis are not completely resolved, and it is closely related to $L$. coccolobae, L. guanensis, L. marmoratus, $L$. nebulosus and $L$. putidus (Fig. 1). However, Lactifluus guadeloupensis is recorded from Grande-Terre of Guadeloupe and it is the only hitherto known Lesser Antillean Lactifluus species found on calcareous soil of coral origin, in contrast to the volcanic origin of the localities of the other Lactifluus species.

\section{Lactifluus marmoratus Delgat, sp. nov. - MycoBank MB828344; Fig. 2d, 5}

Diagnosis. Differs from L. guadeloupensis and L. nebulosus by the slightly larger spores, the larger and especially wider basidia, the presence of branching pleuromacrocystidia and the large isodiametric cells in the pileipellis and stipitipellis.

Typus. MARTINIQUe, Commune du Prêcheur, Anse Lévrier (14.845595 ${ }^{\circ}$, $-61.216511^{\circ}$, alt. $56 \mathrm{~m}$ ), soil with Guapira fragrans, 14 Nov. 2015, Lynn Delgat, LD 15-066 (GENT).

Etymology. Refers to the marbled colour of the pileus.

Pileus $39 \mathrm{~mm}$ diam, convex with slight central depression and deflexed margin; surface chamois-leather like, grey (8E2), with some white, and greyish orange (5B4) and light brown (6D4) spots. Stipe $27 \times 6 \mathrm{~mm}$, cylindrical, somewhat tapering downwards; surface chamois-leather like, greyish brown (6E2) to light brownish grey (6C1, 6D2), marbled with light brown (6D5) spots. Lamellae decurrent, rather distant, with some bifurcations near the margin, white, staining brown; edge even and concolourous. Context white, slightly stuffed, unchanging, dark green blue with guaiac, slowly dark greenish grey with $\mathrm{FeSO}_{4}$. Odour fishy, like fresh fish, shrimps or crayfish. Taste insignificant. Latex rather scarce, watery white, staining brown; taste mild.

Basidiospores broadly ellipsoid to ellipsoid, rarely subglobose, 8.9-10.5-12.1 × 7.3-8.3-9.3 $\mu \mathrm{m}(\mathrm{Q}=(1.11-) 1.13-1.26-$ 1.40 ); ornamentation amyloid, composed of rounded warts, up to $1 \mu \mathrm{m}$ high, mostly isolated, sometimes connected by fine connective lines; plage inamyloid. Basidia 68-85-102 $\times$ 12.5-14-16 $\mu \mathrm{m}$, subclavate, 4-spored. Pleuromacrocystidia 84-134-184 × 7-9-11 $\mu \mathrm{m}$, medium abundant, cylindrical with rounded, mucronate or slightly moniliform apex, some branching in two, thin-walled. Pleuropseudocystidia 4.5-10 $\mu \mathrm{m}$ diam, not emergent; content oleiferic. Lamellar edge fertile. Hymenophoral trama mixed, with hyphae, lactifers and sphaerocytes. Pileipellis a palisade; elements of the suprapellis $22-50-78 \times$ 3-5-8 $\mu \mathrm{m}$, cylindrical to lageniform, with brown intracellular 


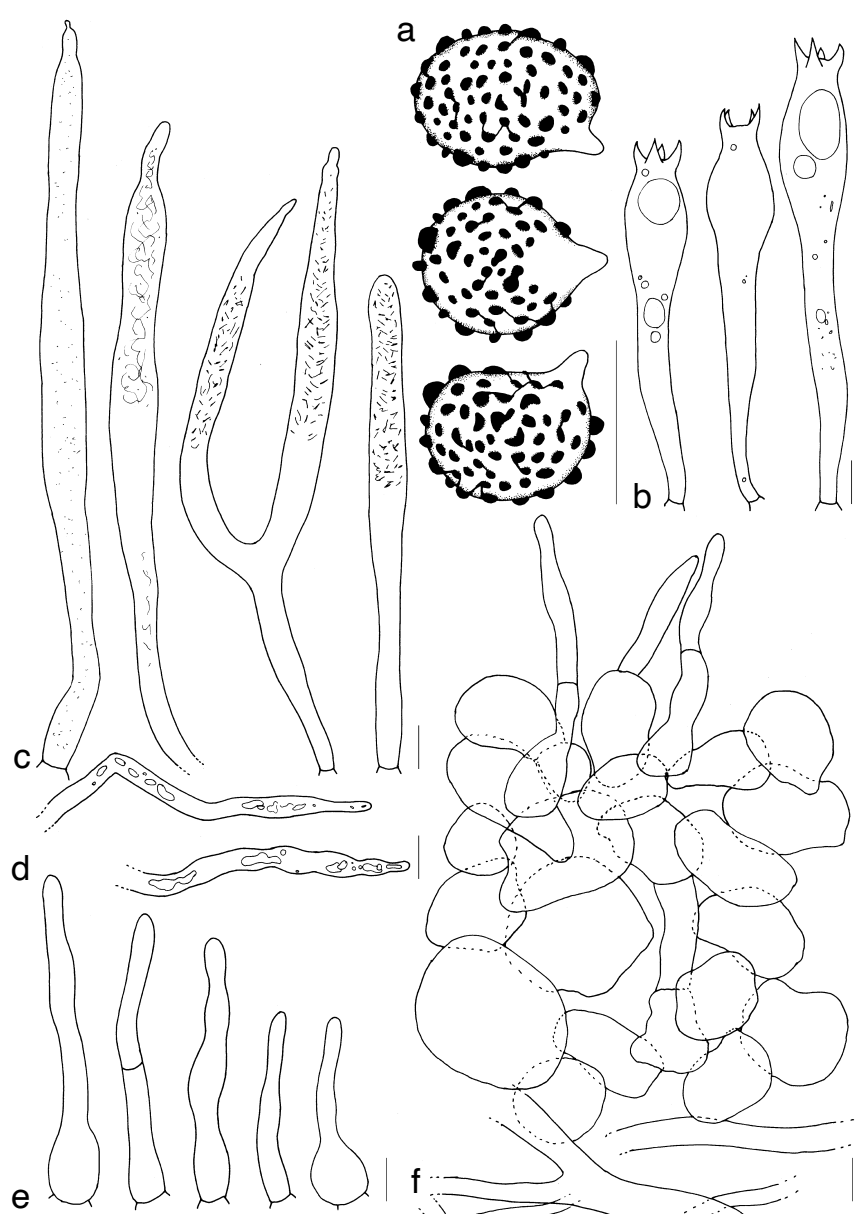

Fig. 5 Lactifluus marmoratus (LD 15-066). a. Basidiospores; b. basidia; c. macrocystidia; d. pseudocystidia; e. pileipellis terminal elements; f. section through the pileipellis. - Scale bars $=10 \mu \mathrm{m}$

pigmentation, often septate; subpellis composed of very large isodiametric cells, $15-45 \mu \mathrm{m}$ diam. Stipitipellis resembling pileipellis, but without brown intracellular pigment in the terminal cells.

Ecology - Found in mesophytic forests with Guapira fragrans.

Distribution - Only known from type locality.

Notes - Lactifluus marmoratus macroscopically resembles $L$. guadeloupensis and $L$. nebulosus. However, there are some subtle macroscopic differences: $L$. nebulosus differs by the lack of brown tinges in the pileus and the white stipe, and L. guadeloupensis differs by the irregular pileus surface and the pruinose lamellae. In contrast to the other species, the context of $L$. marmoratus does not change colour when cut, although this could be caused by the scarcity of the latex in the studied specimen. Microscopically, L. marmoratus differs from both species by the slightly larger spores, the larger and especially wider basidia, the presence of branching pleuromacrocystidia and the large isodiametric cells in the pileipellis and stipitipellis. Molecularly, it is not clear what the most closely related species is to $L$. marmoratus, but it is closely related to $L$. coccolobae, L. guanensis, L. nebulosus and L. putidus (Fig. 1).

Lactifluus nebulosus (Pegler) De Crop, Persoonia 38: 76. 2016 - Fig. 2b, 6

三Lactarius nebulosus Pegler, Kew Bull. 33 (4): 610. 1979.

Pileus 7-83 mm diam, hemispherical with depressed centre and inflexed margin when young, infundibuliform with straight to deflexed margin when adult; surface chamois-leather like,

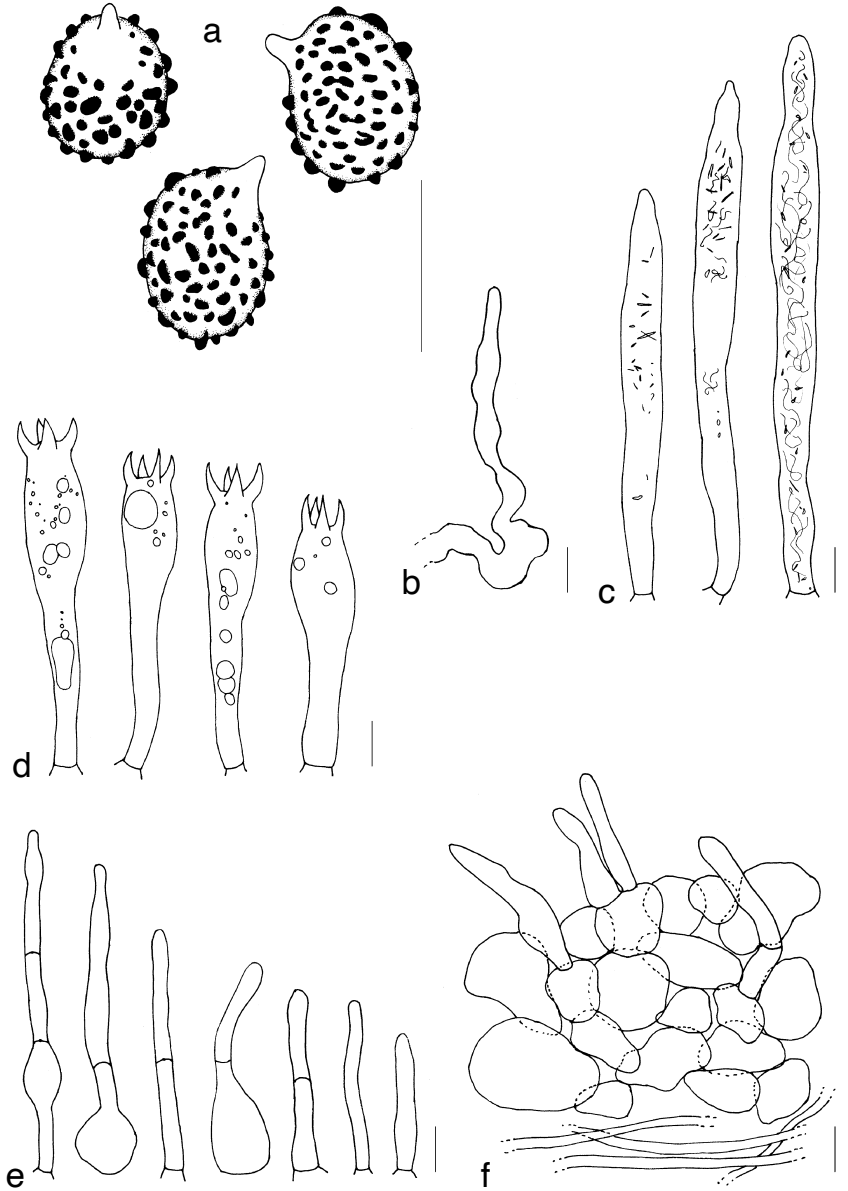

Fig. 6 Lactifluus nebulosus (LD 15-036, LD 15-059, LD 15-061). a. Basidiospores; b. pseudocystidium; c. macrocystidia; d. basidia; e. pileipellis terminal elements; $f$. section through the pileipellis. - Scale bars $=10 \mu \mathrm{m}$.

often slightly wrinkled, grey (4C2, 5B-C2, 5D3, 6B1) and white, with some yellow (4A2-4) areas, and brown spots (5D4). Stipe $5-30 \times 3-15 \mathrm{~mm}$, cylindrical; surface irregular, white, with brown (6D4, 6E5) stains. Lamellae decurrent to deeply decurrent, distant, often bifurcating near the margin, white to cream (4A2), staining brown (5C4, 6E5); edge even and concolourous. Context white, stuffed, turning brown when cut (7D3), with the middle part of the stipe remaining unchanged in adult specimens, dark green-blue with guaiac, dark greenish grey with $\mathrm{FeSO}_{4}$. Odour like Russula xerampelina; shellfish. Taste insignificant, mild. Latex abundant to very abundant in young specimens, watery white, staining brown; taste mild.

Basidiospores broadly ellipsoid to ellipsoid, 7.3-9-9.5-11.3 $(-12.8) \times 5.9-6.9-7.2-8.4(-9.7) \mu \mathrm{m}(\mathrm{Q}=1.09-1.30-1.32-$ $1.46)$; ornamentation amyloid, composed of rounded warts, up to $1 \mu \mathrm{m}$ high, isolated, rarely connected by fine connective lines; plage inamyloid. Basidia 47.5-59.5-72 × 10-11.5-12.5(-13) $\mu \mathrm{m}$, subclavate, 4-spored. Pleuromacrocystidia (54-)59.5$112.5-166 \times 6-9.5-13 \mu \mathrm{m}$, very abundant, cylindrical with rounded, mucronate or slightly moniliform apex, thin-walled. Pleuropseudocystidia very scarce, not emergent, content oleiferic. Lamellar edge fertile. Hymenophoral trama mixed, with hyphae, abundant lactifers and abundant sphaerocytes. Pileipellis a palisade; elements of the suprapellis 18-43-68(-72) $\times 2.5-4-5 \mu \mathrm{m}$, cylindrical to lageniform, often septate; subpellis composed of isodiametric cells. Stipitipellis resembling pileipellis.

Ecology - Found in xerophytic forests with Coccoloba pubescens, Coccoloba swartzii and Guapira fragrans.

Distribution - Only known from the island of Martinique. 
Specimens examined. MARTINIQUE, Réserve naturelle La Caravelle, Commune de Trinité, Tartane, vicinity of ruins of Chateau Dubuc (14.769464 ${ }^{\circ}$, $-60.890001^{\circ}$, alt. $\left.31.2 \mathrm{~m}\right)$, soil with Guapira fragrans, Coccoloba pubescens, 08 Nov. 2015, Lynn Delgat, LD 15-031 (GENT); ibid., (14.769232, $-60.887195^{\circ}$, alt. $\left.24.3 \mathrm{~m}\right)$, soil with Coccoloba pubescens, 08 Nov. 2015, Lynn Delgat, LD 15-036 (GENT); Réserve naturelle La Caravelle, Commune de Trinité, Tartane, close to bar 'Le Phare', above the mangrove, Anse Four à Chaux (14.765185,$-60.897090^{\circ}$, alt. $\left.20.1 \mathrm{~m}\right)$, soil with Coccoloba swartzii, Guapira fragrans, 12 Nov. 2015, Lynn Delgat, LD 15-059 (GENT); ibid., $\left(14.764985^{\circ},-60.897280^{\circ}\right.$, alt. $\left.18.8 \mathrm{~m}\right)$, soil with Coccoloba pubescens, Guapira fragrans, 12 Nov. 2015, Lynn Delgat, LD 15-061 (GENT).

Notes - Lactifluus nebulosus is sometimes confused with $L$. caribaeus, only differing by the absence of grey tinges in the pileus of $L$. caribaeus and its stronger unpleasant odour. However, microscopic differences are clear: L. nebulosus has larger spores, a palisade structure of the pileipellis, and conspicuous macrocystidia, while $L$. caribaeus has a trichoderm and no macrocystidia. Concordant with these clear microscopic differences, $L$. nebulosus and $L$. caribaeus are molecularly not sister species. In contrast, $L$. nebulosus is probably most closely related (although unsupported: bootstrap $=69$ ) to the recently described $L$. guanensis from the British Virgin Isles (Fig. 1). However, this species can easily be distinguished from $L$. nebulosus by the presence of an amyloid plage, the absence of pleurocystidia and the lamprotrichoderm structure of the pileipellis (Crous et al. 2019). Lactifluus nebulosus is also macro- and microscopically similar to L. guadeloupensis sp. nov. and L. marmoratus sp. nov.; for comparison see the notes on those respective species.

\section{Lactifluus guanensis Delgat \& Lodge, Persoonia 43: 375.} 2019

Ecology - Found on sandy soil under Coccoloba uvifera. Isles.

Distribution — Only known from Guana Island, British Virgin

Notes - This recently described species fits morphologically in $L$. sect. Nebulosi, notably because of the dull basidiocarp colours, the brown staining of the latex and context, the unpleasant odour and the spore ornamentation with isolated warts. The placement in this section is confirmed molecularly by the position of the type sequence in the phylogeny (Fig. 1). Compared to $L$. coccolobae, which also occurs on Guana Island, L. guanensis has broader basidia $(9.5-12-14(-14.5) \mu \mathrm{m})$, slightly longer spores $((7.3-) 7.5-9.5-11.4(-11.7) \mu \mathrm{m})$, higher spore ornamentation (up to $1 \mu \mathrm{m}$ high) and non-gelatinised pileipellis (Crous et al. 2019). Compared to Lactifluus species from the Lesser Antilles, L. guanensis is easily distinguishable, notably due to the often amyloid plage, the absence of macrocystidia and the lamprotrichoderm structure of the pileipellis consisting of thick-walled elements. In addition, only $L$. coccolobae was also found in association with Coccoloba uvifera.

Lactifluus murinipes (Pegler) De Crop, Persoonia 38: 76. 2016 - Fig. 2e, 7

三Lactarius murinipes Pegler, Kew Bull. 33 (4): 623. 1979

= Lactifluus castaneibadius (Pegler) De Crop, Persoonia 38: 76. 2016. 三 Lactarius castaneibadius Pegler, Kew Bull. 33 (4): 622.1979

Pileus 8-75 mm diam, plano-convex with inflexed margin when young, infundibuliform with straight to deflexed margin when adult; surface chamois-leather like, sometimes slightly wrinkled, dark brown (6F4-6, 7F4, 8F4-5), sometimes with some lighter areas (5B4, 5D4, 6D4). Stipe 11-30 × 5-14 mm, cylindrical to slightly tapering downwards, white to yellowish white (4A2), turning light brown (5B3, 5C3, 5D4-5, 6D4), sometimes with orange stains (6C6). Lamellae subdecurrent to decurrent, medium to distant, often bifurcating near the margin, slightly transvenose, white to cream (4A2), staining brown (5B3-4 6C6); edge crenulate and concolourous. Context white, firm, slowly turning brown, dark green blue with guaiac, no reaction with $\mathrm{FeSO}_{4}$. Odour weakly sweet. Taste first mild, then acrid to very acrid, sometimes mild when latex is scarce or absent. Latex scarce to abundant, watery white, not changing colour; taste acrid to very acrid or first mild, then acrid to very acrid. Basidiospores subglobose to broadly ellipsoid, some slightly ellipsoid, 6.1-8-8.2-9.8(-10.1) × 5.5-6.5-6.8-8 $\mu \mathrm{m}$ $(\mathrm{Q}=1.04-1.19-1.23-1.36)$, in some collections rare large spores are present $(11.3-14.5 \times 8.6-12.9 \mu \mathrm{m})$; ornamentation amyloid, composed of rounded warts, up to $0.5-1 \mu \mathrm{m}$ high, mostly isolated, sometimes connected by fine connective lines; plage inamyloid. Basidia 50.5-65.5-81 × (8-)8.5-10.5-12 $\mu \mathrm{m}$, subclavate, mostly 4 -spored, sometimes 1 - or 2 -spored. Pleuromacrocystidia 62-102-142 × 7-9-11(-11.5) $\mu \mathrm{m}$, very abundant, cylindrical with rounded, mucronate or rostrate apex, thin-walled. Pleuropseudocystidia very abundant, 4-7 $\mu \mathrm{m}$ diam, not or slightly emergent; positive reaction with sulphovanillin. Lamellar edge fertile. Hymenophoral trama filamentous, with hyphae and abundant lactifers. Pileipellis a trichoderm; elements of the suprapellis $16-61.5-106.5(-150) \times(2-) 2.5-4-5$ $\mu \mathrm{m}$, cylindrical, some septate; subpellis composed of hyphae; with emerging dermatocystidia 41-55.5-70 × 4-5.5-7 $\mu \mathrm{m}$ and dermatopseudocystidia 5.5-7 $\mu \mathrm{m}$ diam. Stipitipellis resembling pileipellis, terminal elements slightly shorter than in the pileipellis, 22-45.5-68.5 × 3-4-5 $\mu \mathrm{m}$.

Ecology - Found in xerophytic forests with Coccoloba diversifolia, Coccoloba pubescens, Coccoloba swartzii, Guapira fragrans, Lonchocarpus sp. and Tabebuia sp.

Distribution - Only known from the island of Martinique.

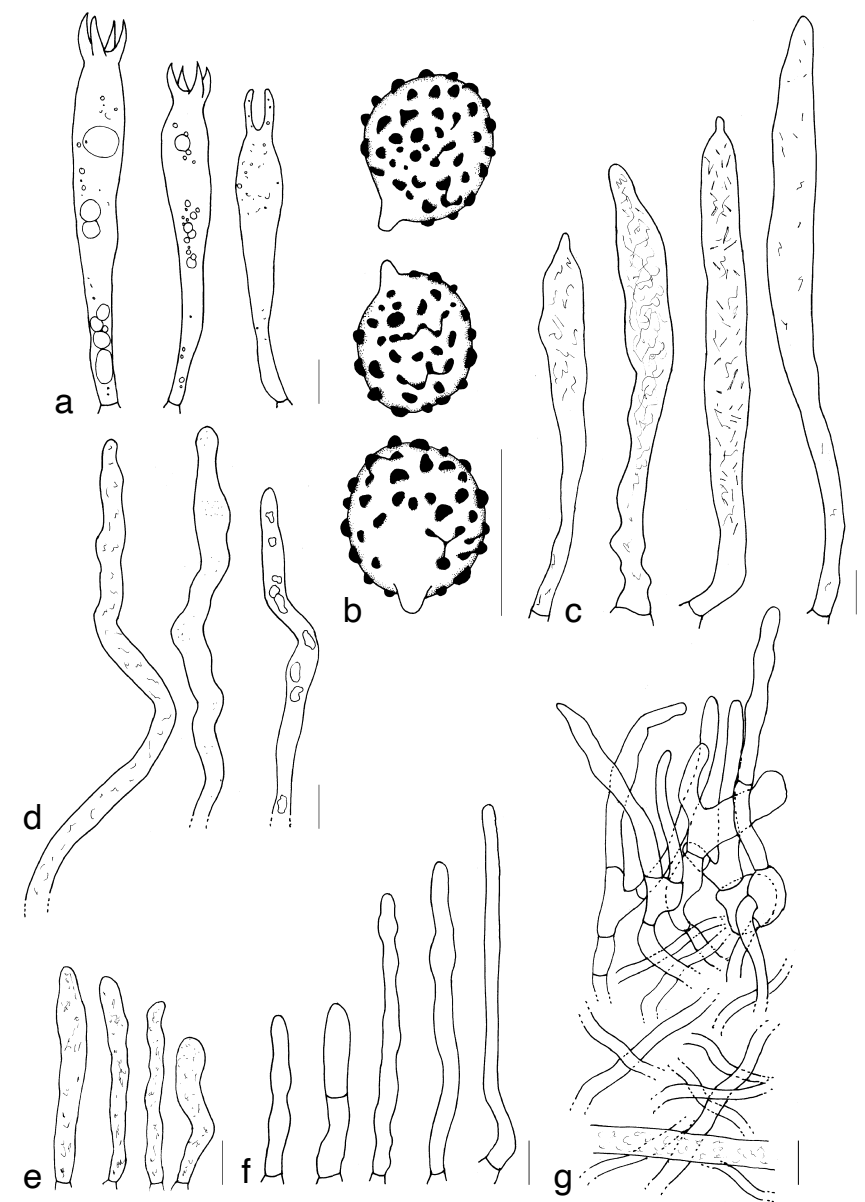

Fig. 7 Lactifluus murinipes (LD 15-015, LD15-018, LD15-020, LD 15-054, LD 15-057). a. Basidia; b. basidiospores; c. macrocystidia; d. pseudocystidia; e. dermatocystidia; f. pileipellis terminal elements; $g$. section through the pileipellis. - Scale bars $=10 \mu \mathrm{m}$. 
Specimens examined. MARTINIQUE, Réserve naturelle La Caravelle, Commune de Trinité, Tartane, close to bar 'Le Phare', above the mangrove, Anse Four à Chaux $\left(14.761724^{\circ},-60.925873^{\circ}\right.$, alt. $\left.16.9 \mathrm{~m}\right)$, soil with Guapira fragrans, 04 Nov. 2015, Lynn Delgat, LD 15-015 (GENT); ibid., (14.767778, $-60.888451^{\circ}$, alt. $13.3 \mathrm{~m}$ ), soil with Guapira fragrans, 04 Nov. 2015, Lynn

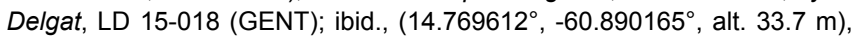
soil with Guapira fragrans, Coccoloba pubescens, 04 Nov. 2015, Lynn Delgat, LD 15-020 (GENT); ibid., (14.765021 ${ }^{\circ},-60.897273^{\circ}$, alt. $\left.18.9 \mathrm{~m}\right)$, soil with Coccoloba swartzii, Guapira fragrans, 12 Nov. 2015, Lynn Delgat, LD 15-054 (GENT); ibid., (14.764985', $-60.897280^{\circ}$, alt. $18.8 \mathrm{~m}$ ), soil with Coccoloba swartzii, Guapira fragrans, 12 Nov. 2015, Lynn Delgat, LD 15-057 (GENT); Réserve naturelle La Caravelle, Commune de Trinité, Tartane, vicinity of ruins of Chateau Dubuc $\left(14.768835^{\circ},-60.889188^{\circ}\right.$, alt. $\left.23.9 \mathrm{~m}\right)$, soil with Coccoloba swartzii, 08 Nov. 2015, Lynn Delgat, LD 15-032 (GENT).

Notes - Lactifluus murinipes is easily distinguishable from the other Antillean species in L. sect. Nebulosi. Macroscopically, it differs by the dark brown pileus, by the latex that tastes acrid and does not turn brown, by the absence of an unpleasant odour and by the absence of a reaction with $\mathrm{FeSO}_{4}$.

Microscopically, the trichodermial pileipellis with abundant conspicuous dermatomyositis helps distinguish L. murinipes from most other similar species.

It was previously already suspected that $L$. castaneibadius and L. murinipes were synonyms (De Crop et al. 2017). Our phylogeny (Fig. 1) confirms the synonymy of these species molecularly, since sequences of the holotypes of both species are part of the same well-supported clade (p-distance $=0.002$ ). They were previously morphologically distinguished from each other by the colour of the stipe, the sulphovanillin reaction of the pseudocystidia and the spore size and shape. However, stipe colour appears quite variable because of the colour-changing
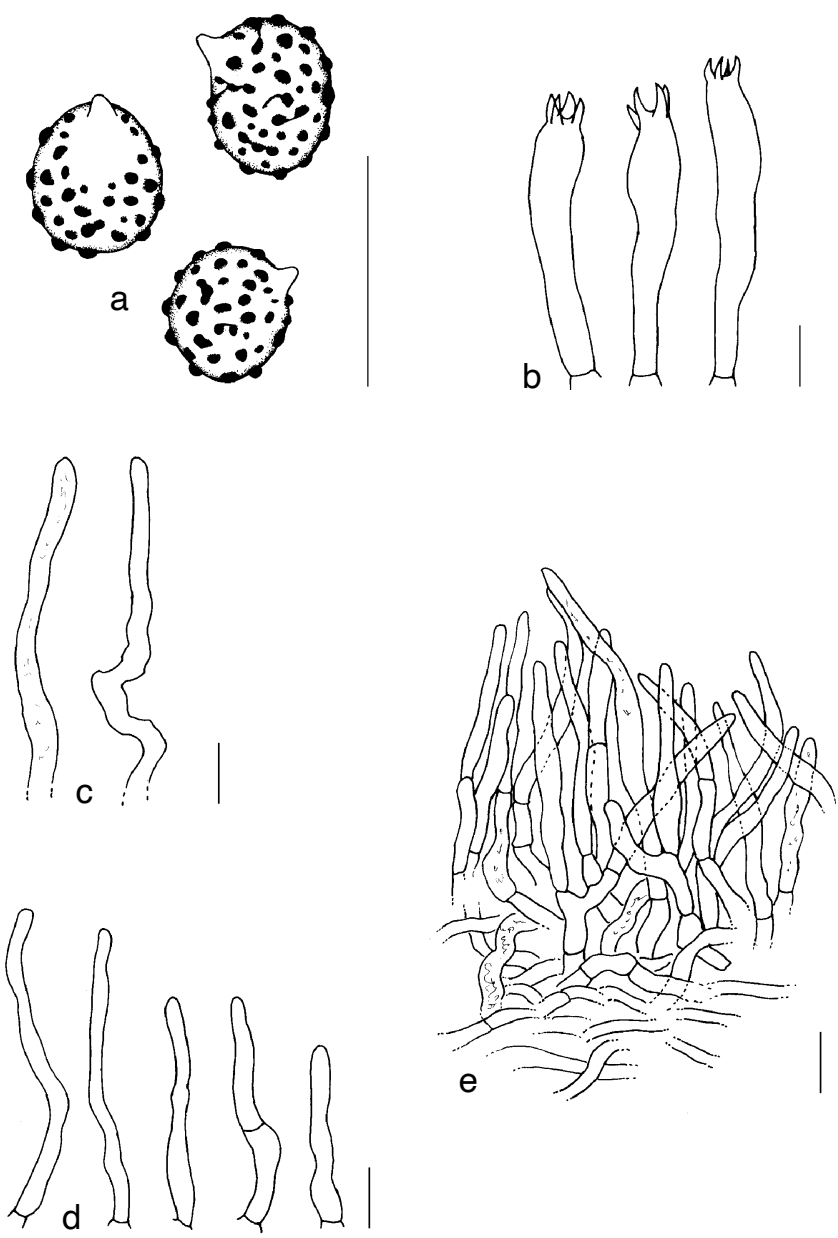

Fig. 8 Lactifluus caribaeus (CL/MART06.014). a. Basidiospores; b. basidia; c. pseudocystidia; d. pileipellis terminal elements; e. section through the pileipellis. - Scale bars $=10 \mu \mathrm{m}$. context. Additionally, it was observed that all recent collections belonging to this clade have a positive sulphovanillin reaction, but the reaction time differs between collections, which could explain the perceived absence of the reaction in collections that react slower. The different spore sizes mentioned in the original description $(7.5-8-9 \times 5.5-7-8 \mu \mathrm{m}$ in L. castaneibadius and $9-9.5-10.5 \times 6.5-7.5-8.5 \mu \mathrm{m}$ in $L$. murinipes) can be considered intraspecific variation. The difference in spore shape $(\mathrm{Q}=1.16$ in $L$. castaneibadius and $Q=1.28$ in $L$. murinipes) could be explained by the difference in spore size, since the measurements of the recent collections of this species show that larger spores generally have slightly bigger $Q$ values. In conclusion, morphological differences between these species were subtle and are now known to be intraspecific variation.

\section{Lactifluus caribaeus (Pegler) Verbeken, Mycotaxon 120: 446. 2012 - Fig. 8}

= Lactarius caribaeus Pegler, Kew Bull. 33 (4): 617. 1979.

Pileus 40-75 mm diam, plano-convex or depressed to almost infundibuliform, with involute margin when young; surface slightly velutinous, slightly wrinkled, ivory yellow, bruising with cinnamon to clay spots. Stipe $20-40 \times 10-25 \mathrm{~mm}$, tapering downwards, very thick and robust, white, turning cinnamon. Lamellae deeply decurrent, slightly distant, thick, occasionally anastomosing, cream; edge entire and concolourous. Context whitish, firm, turning light cinnamon, light green blue with guaiac, rapidly dark green with $\mathrm{FeSO}_{4}$. Odour strong, unpleasant, recalling urine. Taste mild. Latex white, staining cinnamon.

Basidiospores subglobose to broadly ellipsoid, rarely slightly ellipsoid, 6.6-7.6-8.5 × 5.8-6.3-6.8 $\mathrm{mm}(\mathrm{Q}=1.06-1.20-1.35)$; ornamentation amyloid, composed of rounded warts, up to 0.5 $\mu \mathrm{m}$ high, isolated, sometimes connected by fine connective lines; plage inamyloid. Basidia 47.5-59-71 × 8-9-10.5 $\mu \mathrm{m}$, cylindric to subclavate, 4-spored. Pleuromacrocystidia absent. Pleuropseudocystidia 3-9 $\mu \mathrm{m}$ diam, not emergent to emergent; apex rounded or mucronate; content oleiferic. Lamellar edge fertile. Hymenophoral trama mixed, with hyphae, lactifers and sphaerocytes. Pileipellis a trichoderm; elements of the suprapellis 26.5-49-72 × 2.5-3.5-4.5 $\mu \mathrm{m}$, cylindrical, some septate; subpellis composed of hyphae. Stipitipellis resembling pileipellis.

Ecology - Found in xerophytic forests with Coccoloba pubescens.

Distribution - Only known from the island of Martinique.

Specimens examined. MARTINIQUE, Sainte-Luce, Trois Rivières, Ravine Saint-Pierre, towards Ravin Gros Vaisseaux (north of the nationale 5) $\left(14.467552^{\circ},-60.926485^{\circ}\right.$, alt. $\left.22.1 \mathrm{~m}\right)$, soil, 28 Nov. 2006, J.P. Fiard, CL/ MART06.014 (LIP); Réserve naturelle La Caravelle (alt. $5 \mathrm{~m}$ ), soil with Coccoloba pubescens, Myrica coriacea and Zanthoxylon caribaeum, 26 Oct. 1976, J.P. Fiard, J.P. Fiard 818A, holotype (K).

Notes - Only one recent collection of this species was found, which lacks a field description and picture, so the macroscopic part of the description is based on the original description and picture (Pegler \& Fiard 1979, 1983). Lactifluus caribaeus can be recognised macroscopically by the combination of the ivory yellow pileus and the strong, unpleasant odour. Molecularly, $L$. caribaeus is most closely related to $L$. chiapanensis from Mexico (Fig. 1), and microscopically, they share the trichodermial structure of the pileipellis. The only other Lesser Antillean species with this type of pileipellis structure is $L$. $m u$ rinipes. However, L. murinipes is macroscopically clearly distinct from $L$. caribaeus because of the dark brown pileus, the acrid unchanging latex and the absence of an unpleasant odour. In contrast, $L$. nebulosus does look macroscopically similar to $L$. caribaeus and is sometimes confused with this species, as already discussed in the notes on $L$. nebulosus. Another morphologically similar species is $L$. coccolobae, known from 
Puerto Rico and Guana Island (BVI). This species differs from $L$. caribaeus, notably by the gelatinised pileipellis, the adnate and crowded lamellae and its dune habitat in association with Coccoloba uvifera.

Lactifluus chiapanensis (Montoya, Bandala \& Guzmán) De Crop, Persoonia 38: 76. 2016

三 Lactarius chiapanensis Montoya, Bandala \& Guzmán, Mycotaxon 57: 412. 1996.

Ecology — Found in tropical forest with Gymnopodium antigonoides.

Distribution - Known from Chiapas, Mexico.

Notes - Lactifluus chiapanensis fits morphologically in L. sect. Nebulosi, notably because of the brown staining of the latex and context, and the spore ornamentation with isolated warts. It is most closely related to $L$. caribaeus (Fig. 1), from which it can be distinguished by the dark to greyish brown pileus colours and the presence of macrocystidia, measuring 92-110.4 × 10.4-13.6 $\mu \mathrm{m}$ (Montoya et al. 1996).

\section{Lactifluus unnamed clade 1}

Lactifluus lepus Delgat \& Courtec., sp. nov. - MycoBank MB828346; Fig. 2f, 9

Diagnosis. Differs from species of $L$. sect. Nebulosi by the striate pectinate margin, the widely spaced lamellae, the considerably smaller spores, the thick-walled terminal elements of the pileipellis and the presence of many 1- and 2-spored basidia.

Typus. Guadeloupe, Petit-Bourg, Tambour, valley of the Tambour river $\left(16.189618^{\circ},-61.595192^{\circ}\right.$, alt. $\left.22.7 \mathrm{~m}\right), 03$ Sept. 2005, R. Courtecuisse et F. Lurel, RC/Guad 05-029 (LIP).

Etymology. Referring to the many 2-spored basidia with rather long sterigmata, reminding of the silhouette of a hair (lepus).

Pileus $35 \mathrm{~mm}$ diam, convex with slight central depression, margin pectinate-striate, slightly bumpy on the striae but not strongly lumpy; surface clearly rugose to wrinkled, more or less radially in the middle and more concentrically towards the margin in some places, pale yellow with some patches more brownish or rusty, in the centre a bit darker (reminding of the colours of Russula fellea). Stipe $20 \times 7 \mathrm{~mm}$, cylindrical, slightly curved, surface finely pruinose, smooth or slightly wrinkled, cream with pale orange hue. Lamellae decurrent, very distant, somewhat thick, pale cream, edge entire and concolourous. Context very pale cream, staining brown. Odour fruity. Taste not observed. Latex white; taste extremely acrid.

Basidiospores subglobose to broadly ellipsoid, rarely globose, 5.6-6.1-6.6 × 4.8-5.4-5.9(-6) $\mu \mathrm{m}(\mathrm{Q}=1.01-1.14-$ 1.27(-1.28)); ornamentation amyloid, composed of isolated rounded warts, up to $1 \mu \mathrm{m}$ high; plage inamyloid. Basidia $53-65.5-77.5(-79) \times 7.5-8-9 \mu \mathrm{m}$, subclavate, many 1-, 2and 4-spored basidia, rarely 3-spored. Pleuromacrocystidia 49.5-85.5-121.5(-136) ×5-7-8.5 $\mu \mathrm{m}$, abundant, cylindrical to slightly fusiform, sometimes branching, thin-walled, arising from deep in the hymenium. Pleuropseudocystidia very abundant, 3-4 $\mu \mathrm{m}$ diam, sometimes branching, not or slightly emergent. Lamellar edge sterile; marginal cells $20-40 \times 2.5-4 \mu \mathrm{m}$. Subhymenium cellular. Hymenophoral trama filamentous, with hyphae and abundant lactifers. Pileipellis a lampropalisade; elements of the suprapellis 28-78.5-129.5 $\times 4-5-6 \mu \mathrm{m}$, cylindrical, often with subcapitate apex, thick-walled; subpellis composed of isodiametric cells. Stipitipellis a trichoderm; terminal elements as in pileipellis.

Ecology - Found in hygrophytic forests.

Distribution - Only known from the island of Guadeloupe.
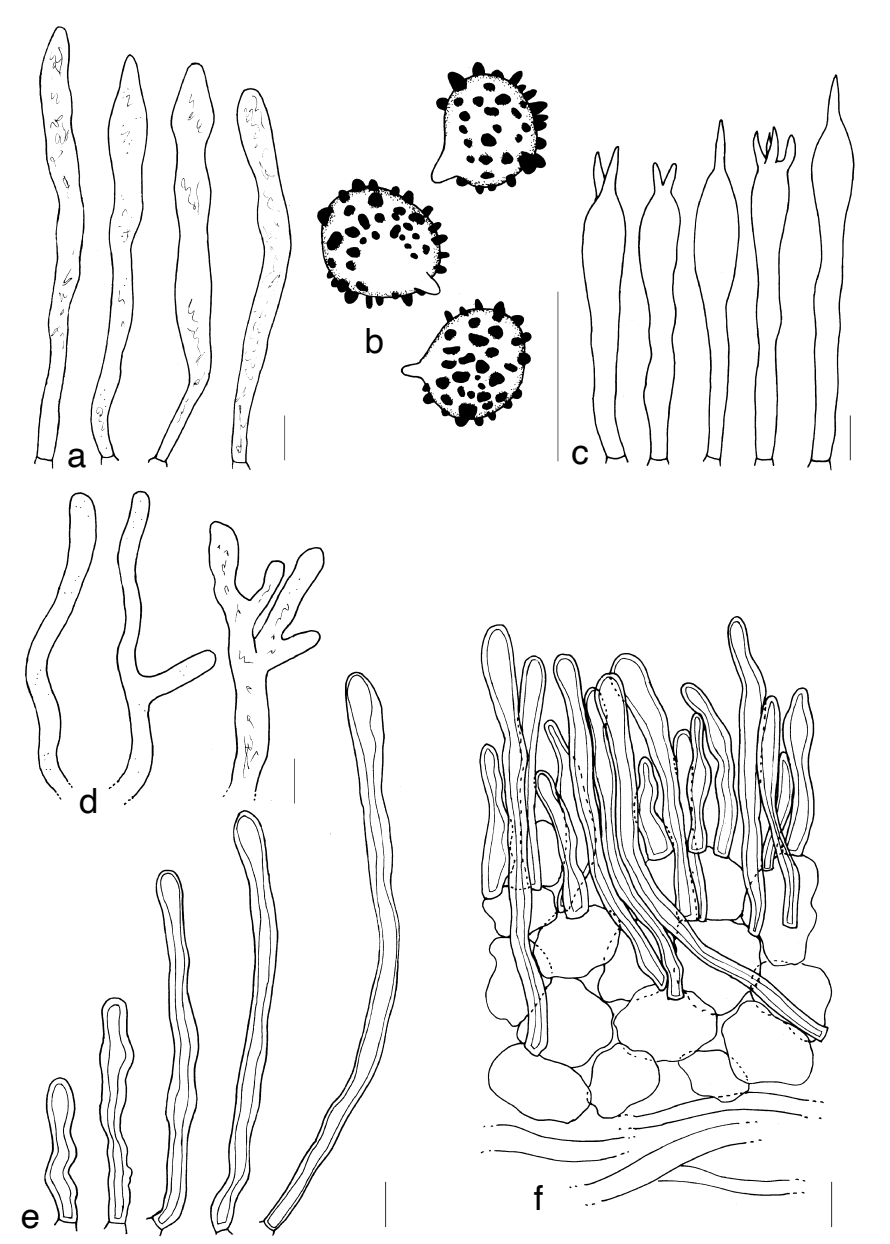

Fig. 9 Lactifluus lepus (RC/Guad 05-029). a. Macrocystidia; b. basidiospores; c. basidia; d. pseudocystidia; e. pileipellis terminal elements; f. section through the pileipellis. - Scale bars $=10 \mu \mathrm{m}$.

Notes - In our phylogeny, as well as in the worldwide molecular analysis of Lactifluus by De Crop et al. (2017), L. lepus is a rather isolated species in $L$. subg. Gymnocarpi. So far only one closely related species is known: an undescribed species from French Guiana (Fig. 1). Lactifluus lepus can easily be distinguished from the species of $L$. sect. Nebulosi by the striate pectinate margin, the widely spaced lamellae, the considerably smaller spores and the thick-walled terminal elements of the pileipellis.

\section{Lactifluus sect. Panuoidei (Singer) Delgat, comb. nov. - Myco- Bank MB831636}

三Lactarius sect. Panuoidei Singer, Kew Bull. 7 (3): 301. 1952. - Typus. Lactifluus panuoides (Singer) De Crop, Persoonia 38: 76. 2016.

三Lactarius panuoides Singer, Kew Bull. 7 (3): 300. 1952. 377. 1993

三 Pleurogala panuoides (Singer) Redhead \& Norvell, Mycotaxon 48:

\section{Lactifluus panuoides (Singer) De Crop, Persoonia 38: 76.} 2016 - Fig. 2g, 10

三 Lactarius panuoides Singer, Kew Bull. 7 (3): 300. 1952. 1993.

三Pleurogala panuoides (Singer) Redhead \& Norvell, Mycotaxon 48: 377.

Basidiocarp pleurotoid. Pileus 10-23 × 8-24 mm diam, spatuliform, irregularly lobed; surface finely pubescent, slightly furfuraceous, wrinkled at the insertion, yellowish cream, staining pale rosy rusty brown, sometimes almost completely purplish brown when old. Stipe excentric and reduced. Lamellae converging 

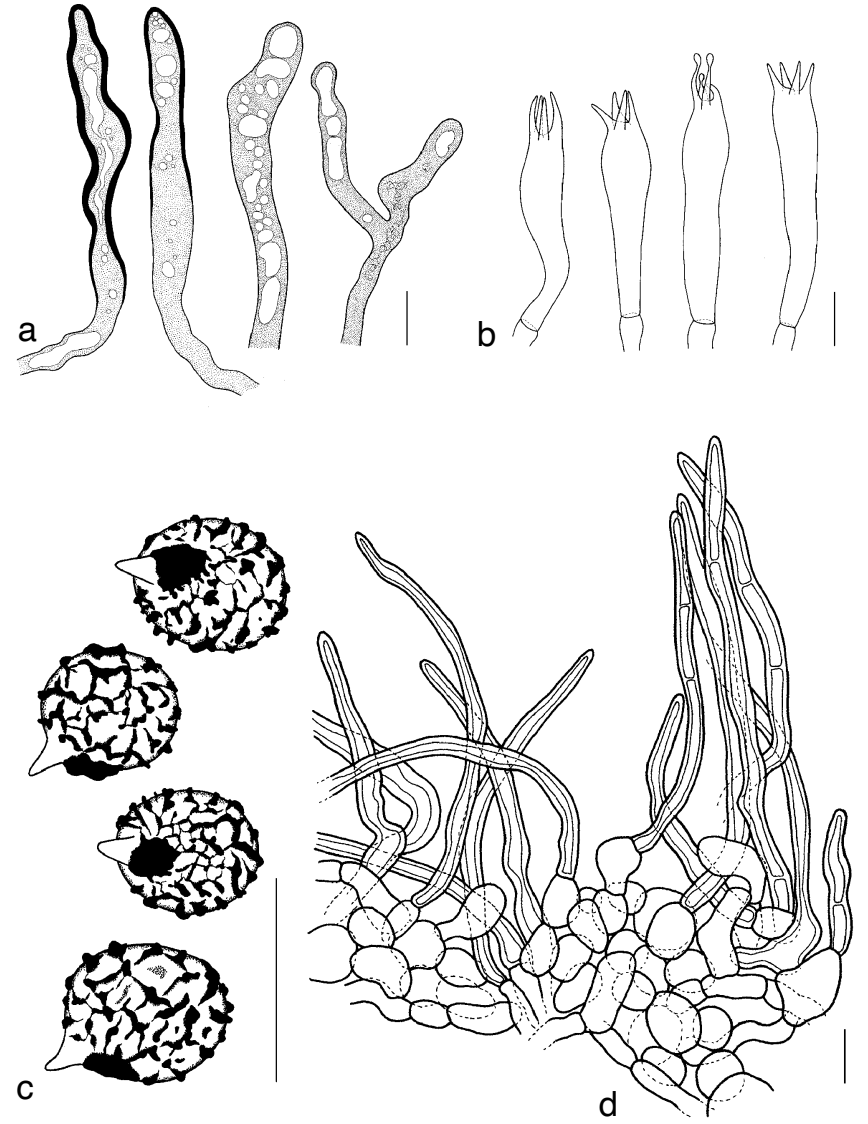

Fig. 10 Lactifluus panuoides (Pegler 3133). a. Pseudocystidia; b. basidia; c. basidiospores; $d$. section through the pileipellis. - Scale bars $=10 \mu \mathrm{m}$.

to the stipe, not crowded, cream, staining pale rusty brown. Context thin. Odour not remarkable. Taste mild. Latex watery white, changing to rosy-brownish. Subiculum tomentose, white to cinnamon.

Basidiospores subglobose to broadly ellipsoid, 5.7-6.8-7.9 $(-8.7) \times 5-5.8-6.7(-6.9) \mu \mathrm{m}(\mathrm{Q}=1.05-1.17-1.29)$, ornamentation amyloid, composed of rounded to irregular warts, up to $1 \mu \mathrm{m}$ high, connected by thick connectives, subreticulate, plage completely amyloid. Basidia 27-37.5-47.5(-48) $\times 8-9-10 \mu \mathrm{m}$, subclavate, 4-spored. Pleuromacrocystidia absent. Pleuropseudocystidia 7.5-9.5 $\mu \mathrm{m}$ diam, thick-walled, content granular and very refringent, slightly emergent. Lamellar edge fertile. Hymenophoral trama filamentous, with hyphae and abundant lactifers. Pileipellis a palisade; elements of the suprapellis $18.5-88-158 \times 4.5-5-6 \mu \mathrm{m}$, cylindrical with obtuse apex, thick-walled, often septate; subpellis composed of isodiametric cells.

Ecology - Found on wood in hygrophytic forests.

Distribution - Known from the Lesser Antilles and French Guiana.

Specimens examined. French GuiAnA, Commune de Regina, Savane-

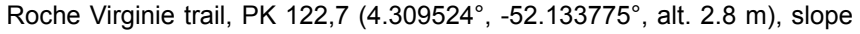
forest, 26 Apr. 2010, R. Courtecuisse, RC/Guy 10-024 (LIP). - GuADELOUPE, Basse-Terre, Sofaia trail, on fallen twigs and debris in hygrophytic forest, 25 Oct. 1977, D.N. Pegler, Pegler 3133 (K). - MARtinique, Fort-de-France, Les Nuages, la Médaille, Rivière Blanche forest, on trunk, 04 Sept. 2003, R. Courtecuisse, RC/Mart 03-077 (LIP). - TRINIDAD, Naranja, 02 Oct. 1949, Dennis $109(\mathrm{~K})$, holotype.

Notes - Lactifluus panuoides is the only pleurotoid Lactifluus species known to occur in the Lesser Antilles. This species has some striking characters: the thick-walled pseudocystidia and the completely amyloid plage, which is common in Russula, but rare in Lactifluus. Other Neotropical pleurotoid species are L. brunellus and L. multiceps, both described from Guyana. Lactifluus panuoides can be easily distinguished from them. Lactifluus brunellus also belongs in L. subg. Gymnocarpi, but it differs from $L$. panuoides by the brown basidiomes with white margin, the shaggy fasciculate subiculum, the slightly larger basidia $(43-53 \times 9-10.5 \mu \mathrm{m})$ and spores $(6.8-8.4 \times$ $(5.6-) 6-7.2 \mu \mathrm{m})$, the inamyloid plage, the rarely connected echinulate-spinuose basidiospore ornamentation and the pileipellis hairs which frequently have swollen bases. Lactifluus multiceps on the other hand belongs to $L$. subg. Lactariopsis. It can be distinguished from $L$. panuoides by the golden yellow to brownish orange basidiomes, the well-developed stipe, the strong acrid taste, the larger spores $(7.2-9.2 \times 6.4-8 \mu \mathrm{m})$, the plage without a large amyloid spot and the longer pileipellis hairs (40-220 $\times 4-7 \mu \mathrm{m})$ which frequently have swollen bases. Additionally, both $L$. brunellus and $L$. multiceps are found in forests dominated by Dicymbe corymbosa (Miller et al. 2002). Molecularly, L. panuoides represents an isolated clade (Fig. 1; De Crop et al. 2017). The collection from Guyana represents a second species in this clade (Delgat, unpubl. results). Given that $L$. panuoides is the type of Lactarius sect. Panuoidei, this clade represents $L$. sect. Panuoidei, which is recombined in this paper.

\section{Lactifluus subg. Lactariopsis (Henn.) Verbeken}

Lactifluus sect. Neotropicus J. Duque, Delgat, Verbeken, M.A. Neves \& A.A. Carvalho, Syst. Biodivers. 18: in press. 2020.

Lactifluus venezuelanus (Dennis) De Crop, Persoonia 38: 77. 2016 - Fig. $2 \mathrm{~h}, 11$

三Lactarius venezuelanus Dennis, Kew Bull. Add. Ser. 3: 467. 1970.

Pileus 28-80 mm diam, convex with deep central depression, striate for a $1 / 3$ to a $1 / 2$ of the radius; surface smooth to slightly bumpy, pale apricot orange to bright brownish orange, hygrophanous. Stipe $15-35 \times 4-10 \mathrm{~mm}$, tapering downwards, fistulose; surface apically with small ridges which are continuing from the decurrent teeth of the gills, pale apricot, rustier towards the base. Lamellae subdecurrent to decurrent, not crowded, slightly pruinose, yellowish cream to pale rusty ochre; edge entire and concolourous. Context white to very pale apricot. Odour weak, more or less fruity or like rubber. Taste insignificant or slightly acrid, very astringent in young specimens. Latex white, quickly disappearing, hence absent in most specimens, not changing colour.

Basidiospores subglobose to broadly ellipsoid, 5.9-6.6-6.8$7.7 \times 5.2-5.6-5.8-6.5 \mu \mathrm{m}(\mathrm{Q}=1.06-1.14-1.17-1.34(-1.39))$; ornamentation amyloid, composed of rounded to irregular warts, up to $1 \mu \mathrm{m}$ high, often connected by lower connective lines, forming an incomplete reticulum; plage inamyloid. Basidia 34.5$43-52 \times 8-10-11.5(-12) \mu \mathrm{m}$, subclavate, mostly 4-spored, some 1 - and 2-spored present. Pleurocystidia absent. Pleuropseudocystidia abundant, 6-10 $\mu \mathrm{m}$ diam, not or slightly emergent. Lamellar edge sterile; marginal cells 15.5-25-34.5 $\times 2.5-3.5-4.5 \mu \mathrm{m}$, narrowly cylindric to subfusiform, often tapering near apex. Hymenophoral trama mixed, with hyphae, lactifers and sphaerocytes. Pileipellis a palisade; elements of the suprapellis $8-65-122.5 \times 2.5-3-3.5(-4) \mu \mathrm{m}$, cylindrical with obtuse apex, sometimes septate; subpellis composed of isodiametric cells. Stipitipellis resembling pileipellis.

Ecology - Found in hygrophytic or mesophytic forests with Guapira fragrans.

Distribution - Known from the islands of Martinique and Guadeloupe. 


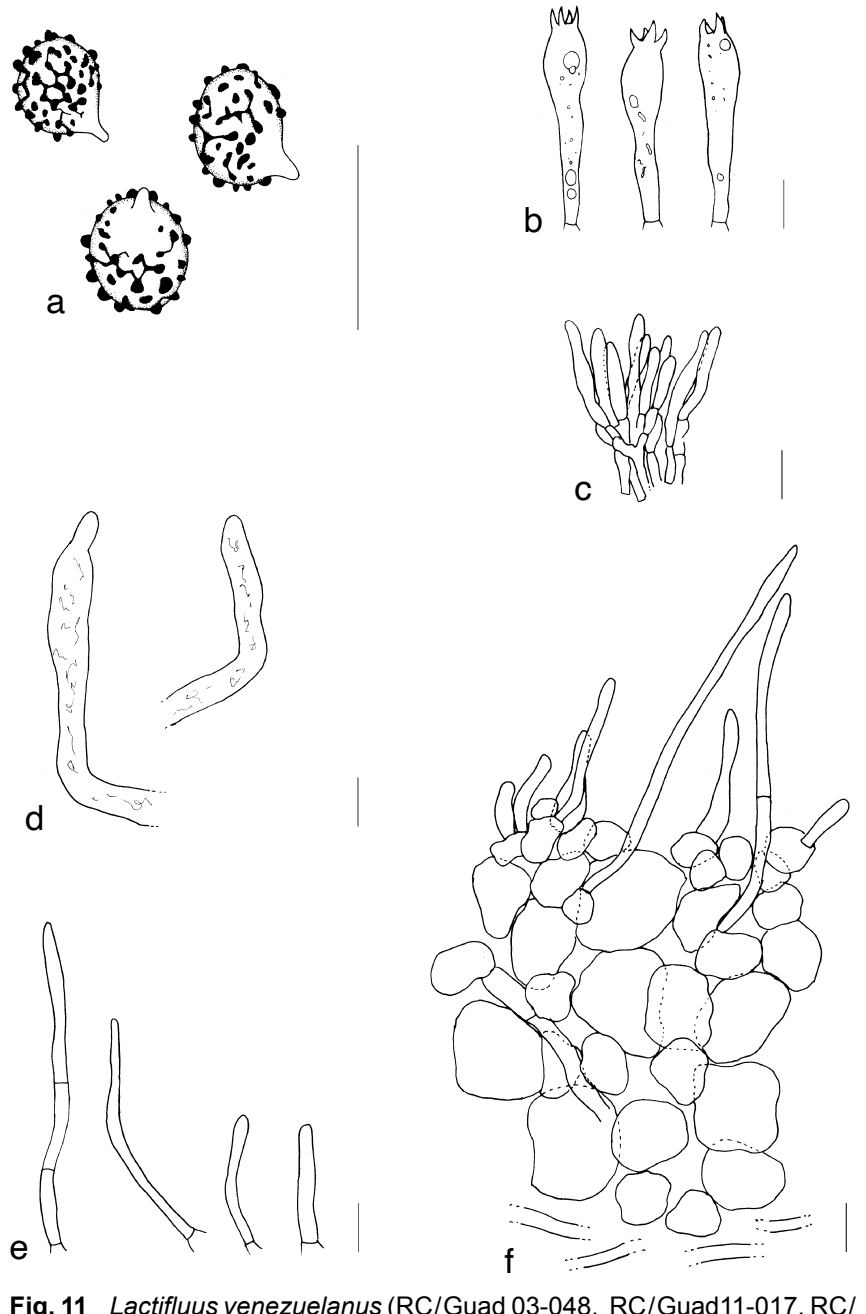

Fig. 11 Lactifluus venezuelanus (RC/Guad 03-048, RC/Guad11-017, RC/ Mart 03-120). a. Basidiospores; b. basidia; c. marginal cells; d. pseudocystidia; e. pileipellis terminal elements; f. section through the pileipellis. - Scale bars $=10 \mu \mathrm{m}$.

Specimens examined. Guadeloupe, Basse-Terre, commune de SaintClaude, Beausoleil, Trace du plateau Dimba (16.026758 ${ }^{\circ},-61.702051^{\circ}$, alt. 440.6 m), 09 Sept. 2003, R. Courtecuisse, RC/Guad 03-048 (LIP); Basse-Terre, Petit-Bourg, Route de la Traversée, near the national park of Guadeloupe, 14 Aug. 2010, P.-A. Moreau, PAM/GUAD 10.037 (LIP); Basse-Terre, Goyave, Chutes de Moreau, 05 Aug. 2011, R. Courtecuisse, RC/Guad11-017 (LIP). - MARTINIQUe, Fort-de-France, Plateau Perdrix, 05 Sept. 2003, R. Courtecuisse, RC/Mart 03-120 (LIP).

Notes - Lactifluus venezuelanus is easily distinguishable from other Antillean Lactifluus species due to the orange striate pileus, the apical ridges on the stipe and the absence of latex in most fruiting bodies. This species is placed in $L$. subg. Lactariopsis, which is confirmed morphologically by the absence of true pleurocystidia and the absence of a colour change of the context and/or latex as in most species of this subgenus. The most closely related described species is $L$. subiculatus from Guyana (Fig. 1), which shares the striate margin of the pileus and the absent or scarce latex. This species can hardly be confused with $L$. venezuelanus because of the smaller fruiting bodies $(9-30 \mathrm{~mm})$, the presence of a well-developed subiculum, the larger and much wider basidia $(45-60 \times 15-18$ $\mu \mathrm{m}$ wide) and the larger spores (7.6-9.2(-9.6) × 6.4-7.6 $\mu \mathrm{m})$ (Miller et al. 2012). The most closely related Antillean species is L. neotropicus (Fig. 1), which can easily be distinguished from $L$. venezuelanus because of the presence of an annulus, the absence of a striate margin and the presence of thick-walled terminal elements in the pileipellis.
Lactifluus neotropicus (Singer) Nuytinck, Mycotaxon 118: 450, 2011 - Fig. 12

三Lactarius neotropicus Singer, Kew Bull. 7 (3): 299. 1952.

Pileus 30-40 mm diam, convex with central depression; surface smooth at the centre, slightly velutinous, with indistinct squamules towards the margin, brown to umber, with a paler ochraceous zone at the margin. Stipe 10-15 × 7-8 mm, cylindrical or tapering downwards, solid, pale buff, with apical annulus just below lamellae insertion; annulus narrow, membranous with a fibrillose margin, concolourous with the stipe surface. Lamellae adnexed to subdecurrent, crowded, thin, pale buff; edge concolourous. Context pale ochraceous buff to pale vinaceous cinnamon, unchanging. Odour none. Taste very acrid. Latex watery white, scarce.

Basidiospores subglobose to broadly ellipsoid, 6.2-7-7.9(-8) $\times 5.3-6.1-6.9(-7) \mu \mathrm{m}(\mathrm{Q}=1.03-1.16-1.30(-1.36))$; ornamentation amyloid, composed of rounded warts, up to $0.5 \mu \mathrm{m}$ high, often connected by lower connective lines, forming an incomplete reticulum; plage inamyloid. Basidia 30-37-43.5 $\times$ 8.5-9.5-11 $\mu \mathrm{m}$, subclavate, 4-spored. Pleurocystidia absent. Pleuropseudocystidia not observed. Hymenophoral trama mixed, with hyphae, lactifers and sphaerocytes. Pileipellis a palisade; elements of the suprapellis $18-54.5-117.5 \times 3.5-6-8.5$, cylindrical with obtuse apex, sometimes tapering near the top, thick-walled; subpellis composed of isodiametric cells.

Ecology - Found in hygrophytic forests.

Distribution - Only known from type locality.
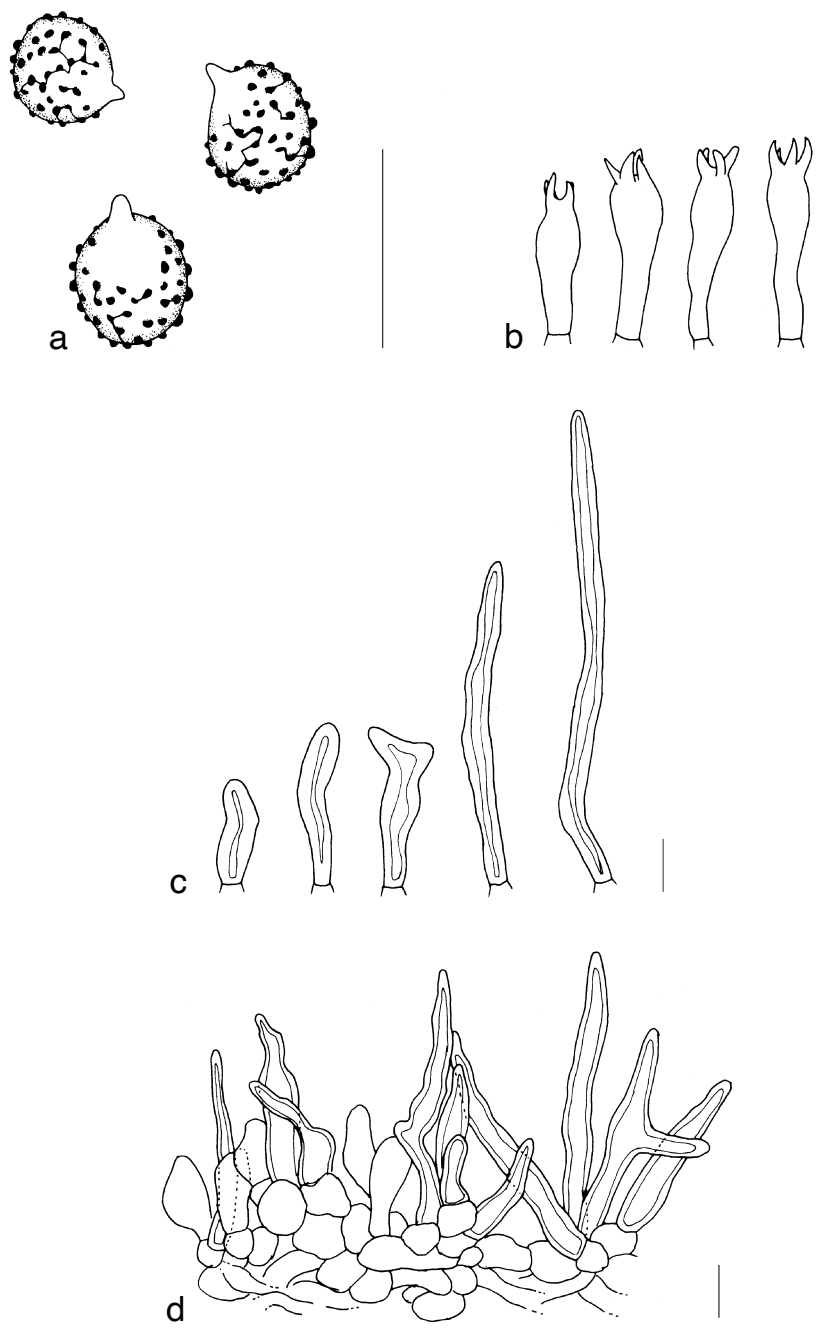

Fig. 12 Lactifluus neotropicus (R.W.G. Dennis 97). a. Basidiospores; b. basidia; c. pileipellis terminal elements; $d$. section through the pileipellis. - Scale bars $=10 \mu \mathrm{m}$. 
Specimens examined. TRINIDAD, Diego Martin, between Maqueripe trail and North Post, 30 Sept. 1949, R.W.G. Dennis, R.W.G. Dennis 97 (K), holotype.

Notes - The holotype of L. neotropicus clusters in the phylogeny together with a collection from French Guiana (Fig. 1), but since only ITS1 is available for the holotype and ITS variability is relatively low in L. sect. Neotropicus, further research is necessary to determine whether this collection could represent L. neotropicus. Since no certain recent collections were found of L. neotropicus, the macroscopic part of the description is based on the original description (Singer 1952). Besides the holotype, two other collections identified as $L$. neotropicus exist, collected in 1977 by Fiard. However, one of them was not available for loan due to the scarcity of the material. Microscopical study of the second collection, i.e., J.P. Fiard 1043A from Guadeloupe, showed that, compared to the holotype, this collection has much longer basidia (55-64.5-80 × 7-8.5-9.5 $\mu \mathrm{m})$ and subcapitate pileipellis hairs, which suggest it could represent a new species.

Aside from this putative new species, L. neotropicus is the only species in the Antilles with velum. This velum, together with the absence of a striate margin and the presence of thick-walled terminal elements in the pileipellis, makes $L$. neotropicus easily distinguishable from $L$. venezuelanus. Both species belong in $L$. subg. Lactariopsis, which is the only subgenus in which secondary velum is observed (Montoya et al. 2012). Another Neotropical Lactifluus species which has velum is $L$. annulifer, which is described from the Brazilian Amazon. Lactifluus annulifer is quite similar to $L$. neotropicus but differs notably by the mild taste of the context, the much larger spores $(8.8-13 \times 8-10$ $\mu \mathrm{m})$ and the presence of macrocystidia (Singer et al. 1983).

Lactifluus sect. Albati (Bataille) Verbeken, Mycotaxon 118: 451. 2011

Lactifluus domingensis Delgat \& Angelini, IMA Fungus 10 (14): 7.2019

Ecology - Found in montane forests with Pinus occidentalis. Distribution - Only known from Dominican Republic, on the island of Hispaniola.

Notes - This recently described species fits morphologically in $L$. sect. Albati, because of the large white basidiomes, the acrid taste and the velutinous cap. The placement in this section is supported molecularly by the position of the type sequence in the phylogeny (Fig. 1). Compared to L. hallingii, which also belongs in L. sect. Albati, but occurs in Central America, $L$. domingensis has slightly higher spore ornamentation (up to $1.7 \mu \mathrm{m})$, somewhat shorter basidia ((42-)43-53-63.5 $\times$ 9.5-12.5-15.5 $\mu \mathrm{m})$, somewhat differently shaped macrocystidia (i.e., more often a mucronate or moniliform apex, more rarely with a rounded or tapering apex) and a loosely arranged cutis to trichoderm as a pileipellis. In addition, L. hallingii is associated with Quercus, while L. domingensis is associated with Pinus occidentalis (Delgat et al. 2019).

Lactifluus hallingii Delgat \& De Wilde, IMA Fungus 10 (14): 10. 2019

Ecology - Found in montane forests with Quercus humboldtii, Quercus seemanii, Quercus copeyensis, Quercus sp.

Distribution - Known from Costa Rica, Panama and Colombia.

Notes - This recently described species fits morphologically in $L$. sect. Albati, because of the large white basidiomes, the acrid taste and the velutinous cap. The placement in this section is confirmed molecularly by the position of the type sequence in the phylogeny (Fig. 1). For a comparison with L. domingensis, see the notes on $L$. domingensis.

Lactifluus subg. Pseudogymnocarpi (Verbeken) De Crop, Persoonia 38: 75. 2016

Lactifluus sect. Polysphaerophori (Singer) Verbeken, Mycotaxon 120: 445. 2012

Lactifluus pegleri (Pacioni \& Lalli) Delgat, comb. nov. - MycoBank MB826723; Fig. 2i, 13

三 Lactarius pegleri Pacioni \& Lalli, Mycotaxon 44 (1): 182. 1992.

Pileus 13-90 mm diam, hemispherical with involute margin and central depression when young, infundibuliform with straight margin when adult; surface slightly velutinous, wrinkled near the margin, burgundy red (9D7-9E4-10D4) with some paler, more orange areas $(5 A 4-6,5 B 5,6 B 3,7 D 3)$, especially near the margin. Stipe $11-50 \times 6-20 \mathrm{~mm}$, cylindrical; surface slightly velutinous, reddish yellow-orange $(4 \mathrm{~A} 4,5 \mathrm{~A} 3-4,6 \mathrm{~A} 2,6 \mathrm{~B} 3$, 7C3, 8C4, 8D5). Lamellae subdecurrent to decurrent, rather distant, some intervenose, some bifurcating near the margin, cream (3A2, 4A2); edge even and concolourous. Context white, firm, slowly dark green blue with guaiac, slowly darkening with $\mathrm{FeSO}_{4}$. Odour insignificant. Taste mild. Latex scarce to abundant, watery white, not changing colour, taste mild.

Basidiospores broadly ellipsoid, some subglobose or ellipsoid, $6.8-7.4-8.2-9.3 \times 5.5-6.1-6.7-7.5 \mu \mathrm{m}(\mathrm{Q}=1.06-1.22-$ 1.38 ); ornamentation amyloid, composed of rounded warts,
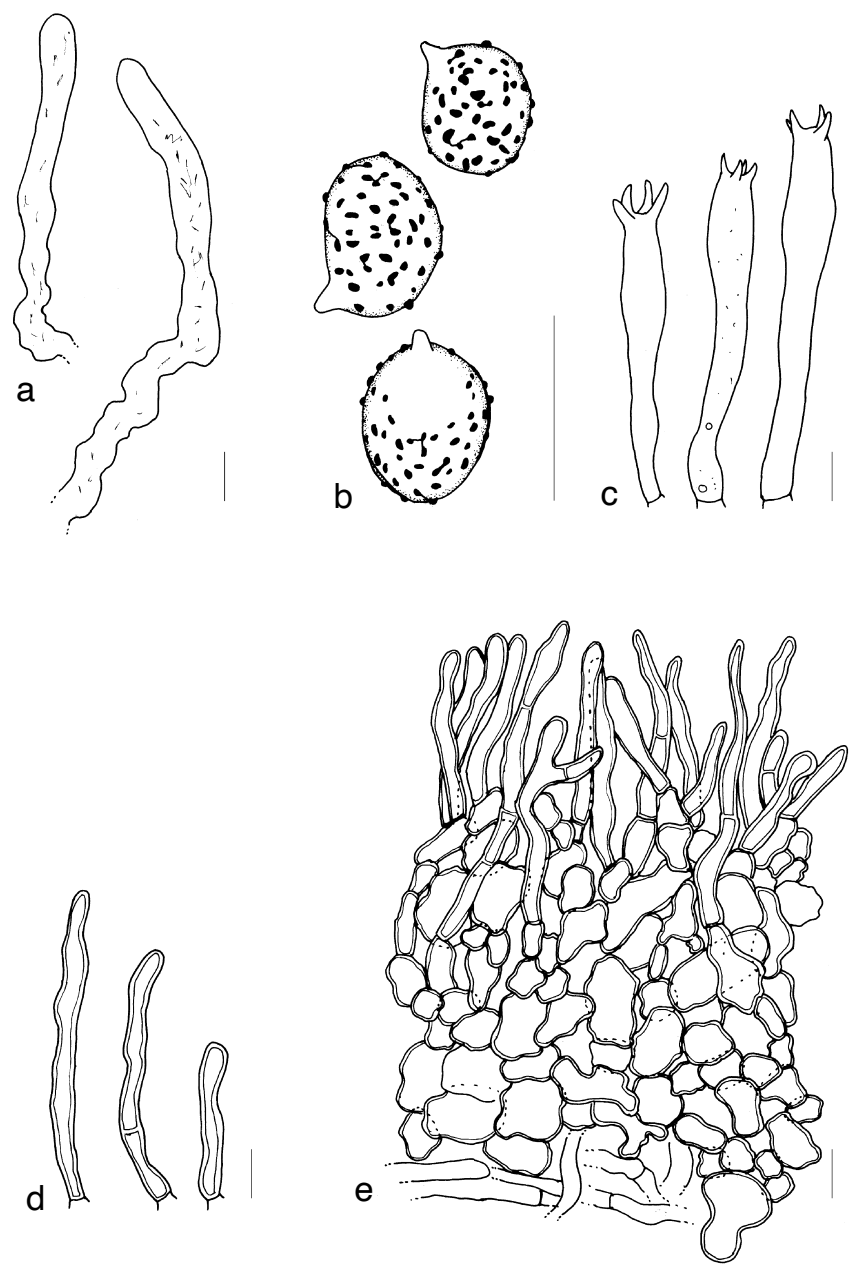

Fig. 13 Lactifluus pegleri (LD 15-042, LD15-049). a. Pseudocystidia; b. basidiospores; c. basidia; d. pileipellis terminal elements; e. section through the pileipellis. - Scale bars $=10 \mu \mathrm{m}$. 
up to $0.2-0.5 \mu \mathrm{m}$ high, mostly isolated, sometimes connected by fine connective lines; plage inamyloid. Basidia (51-)53$68.5-84.5 \times 7-8.5-10(-10.5) \mu \mathrm{m}$, cylindrical to subclavate, slightly refringent, 4-spored, often arising deep in the hymenium. Pleurocystidia absent. Pleuropseudocystidia 6-7.5 $\mu \mathrm{m}$ diam, not emergent. Lamellar edge fertile. Hymenophoral trama cellular, with sphaerocytes and broad lactifers. Pileipellis a palisade; elements of the suprapellis $16.5-52-87 \times 3.5-4-4.5$, cylindrical with obtuse apex, slightly thick-walled, some septate; subpellis composed of rather small, slightly thick-walled isodiametric cells. Stipitipellis resembling pileipellis.

Ecology - Found in xerophytic forests with Coccoloba pubescens and Guapira fragrans.

Distribution - Only known from the island of Martinique.

Specimens examined. MARTINIQUE, Réserve naturelle La Caravelle, Commune de Trinité, Tartane, close to bar 'Le Phare', above the mangrove, Anse Four à Chaux $\left(14.761724^{\circ},-60.925873^{\circ}\right.$, alt. $\left.16.9 \mathrm{~m}\right)$, soil with Guapira fragrans, 04 Nov. 2015, Lynn Delgat, LD 15-014 (GENT); ibid., (14.762887², $-60.897124^{\circ}$, alt. $10.6 \mathrm{~m}$ ), soil with Coccoloba pubescens, Guapira fragrans, 12 Nov. 2015, Lynn Delgat, LD 15-049 (GENT); Réserve naturelle La Caravelle, Commune de Trinité, Bois de Pointe Rouge, soil with Coccoloba pubescens, Guapira fragrans, 10 Nov. 2015, Lynn Delgat, LD 15-042 (GENT).

Notes - Lactifluus pegleri is an easily recognizable species because of its fleshy habitus and notable burgundy red to orange pileus colour. It is known from several localities in Martinique and additional specimens collected during the 2003-2015 field trips (coll. R. Courtecuisse) are deposited in LIP. This species was first identified by Pegler as L. hygrophoroides, and only later proposed as a new species (Lalli \& Pacioni 1992). Indeed, macroscopically, L. pegleri strongly reminds of $L$. hygrophoroides. However microscopically, L. hygrophoroides has more elongated spores $(Q=1.35)$ and a more reticulate spore ornamentation (Lalli \& Pacioni 1992). Additionally, the ecology of these two species is very different, with $L$. hygrophoroides occurring with temperate broad-leaved species (e.g., oaks). An important distinguishing feature reported in the original description, was the trichodermial structure of the pileipellis (Lalli \& Pacioni 1992), however, our microscopical study of the collections shows that $L$. pegleri has a lampropalisade structure as a pileipellis, similar to $L$. hygrophoroides. Despite the similarity between these two species, the phylogeny confirms that they are different species and shows that they are not even closely related, although they both belong to $L$. subg. Pseudogymnocarpi (Fig. 1). Lactifluus pegleri is the only Antillean species in this subgenus and like most species in this subgenus, L. pegleri has a lampropalisade, unchanging latex and an orange to reddish brown pileus. The most closely related species is L. veraecrucis from Mexico (Fig. 1), which strongly resembles L. pegleri according to the original description (Singer 1973) and a microscopic study of the isotype. Recent collections of $L$. veraecrucis are needed to find characters, besides their different distribution, to distinguish them. Given that $L$. veraecrucis has been designated as the type of $L$. sect. Polysphaerophori, $L$. pegleri belongs to this section as well. Next to these two Central American species, this section also contains at least three unnamed South American species. Species previously classified in this section based on morphology, such as $L$. venezuelanus and $L$. nebulosus, do not belong in this section and the section is in need of an updated morphological description.

Lactifluus veraecrucis (Singer) Verbeken, Mycotaxon 120: 445. 2012

三Lactarius verae-crucis Singer, Beih. Sydowia 7: 104. 1973

= Lactarius veraecrucis Singer. 1973.

Ecology - Found in tropical rain forest.

Distribution - Known from Chiapas and Veracruz, Mexico.
Notes - Lactifluus veraecrucis represents the type species of $L$. sect. Polysphaerophori. Its lamellar trama is completely cellular, and the presence of sphaerocytes in the trama was one of the original characters used to define this section, which caused numerous species to be included in this section. Currently only two described species are confirmed to belong in this section: $L$. veraecrucis and $L$. pegleri. Lactifluus veraecrucis is closely related to $L$. pegleri (Fig. 1) from the Lesser Antilles, and morphologically closely resembles it. The spores of $L$. veraecrucis are slightly more subglobose $(7-8.3 \times 6.5-7 \mu \mathrm{m})$ than those of $L$. pegleri, but the easiest way to distinguish them is their different distribution. Recent collections of $L$. veraecrucis could help to find additional characters to distinguish between these species.

\section{KEY TO CARIBBEAN SPECIES}

1. Context and latex not changing colour . . . . . . . 2

1. Context, pileus, lamellae, stipe and/or latex changing to brown. . . . . . . . . . . . . . . . . 4

2. Basidiospore ornamentation mostly composed of isolated warts; basidia 51-84.5 $\mu \mathrm{m}$ long; pileus colour burgundy red with orange; context mild. . . . . . . . . . . L. pegleri

2. Basidiospore ornamentation with many connectives between the warts; basidia shorter, 30-52 $\mu \mathrm{m}$ long; pileus colour orange to brown; context slightly to very acrid (subg. Lactariopsis) . . . . . . . . . . . . . . . . 3

3. Annulus or velar remnants present on the stipe; pileus not striate; terminal elements of the pileipellis thick-walled. .

L. neotropicus

3. Annulus or velar remnants absent; pileus rather thin and striate; terminal elements of the pileipellis thin-walled. .

L. venezuelanus

4. Basidiocarp large and white; pileus velutinous; context acrid; associated with Pinus occidentalis L. domingensis

4. Not this combination of characters (subg. Gymnocarpi) 5

5. Habitus pleurotoid . . . . . . . . . . . . . panuoides

5. Habitus agaricoid; basidiospores with isolated verrucae 6

6. Pileipellis structure a trichoderm; pleurocystidia absent 7

6. Pileipellis structure a trichopalisade to palisade; pleuromacrocystidia $49.5-184 \times 5-13 \mu \mathrm{m} \ldots \ldots \ldots \ldots \ldots 9$

7. Terminal elements of the pileipellis thick-walled ....... L. guanensis

7. Terminal elements of the pileipellis thin-walled . . . . 8

8. Pileipellis gelatinised, found in dunes with Coccoloba uvifera. . . . . . . . . . . . . . . . . . . L. coccolobae

8. Pileipellis not gelatinised, found in forests with other Coccoloba species. . . . . . . . . . . . . L. caribaeus

9. Pileus surface very irregular with a striate pectinate mar-

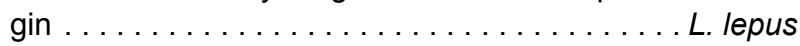

9. Pileus surface rather smooth or wrinkled, margin not striate .................... 10

10. Taste of latex and context acrid; latex not changing colour; no reaction with $\mathrm{FeSO}_{4}$; odour not distinctly unpleasant .

L. murinipes

10. Taste of latex and context mild; latex changing colour to brown; context reacting green-grey with $\mathrm{FeSO}_{4}$; odour distinctly unpleasant $\ldots \ldots \ldots \ldots \ldots \ldots \ldots \ldots$

11. Pileus colour brown, often light brown in the centre; pileus surface often strongly wrinkled; odour characteristically very strongly unpleasant; terminal elements up to $55 \mu \mathrm{m}$

L. putidus

11. Pileus colour marbled; pileus surface at most slightly wrinkled, surface chamois-leather like; terminal elements up to $68-91.5 \mu \mathrm{m} \ldots \ldots \ldots \ldots \ldots \ldots \ldots \ldots \ldots$ 
12. Brown tinges present in pileus; stipe colour variable (greydirty cream); basidiospores broadly ellipsoid (average $\mathrm{Q}=1.24-1.26) \ldots \ldots \ldots \ldots \ldots \ldots \ldots \ldots \ldots \ldots \ldots$

12. No brown tinges in pileus; stipe white; basidiospores ellipsoid (average $Q=1.30-1.32$ ) . . . . . L. nebulosus

13. Basidia rather broad (average width $14 \mu \mathrm{m}$ ); large sphaerocytes $(15-45 \mu \mathrm{m})$ in the pileipellis .... . L. marmoratus

13. Basidia rather slender (average width $10.5 \mu \mathrm{m}$ ); small sphaerocytes (up to $15 \mu \mathrm{m}$ ) in the pileipellis . . . . . . . . . . $\ldots \ldots \ldots \ldots \ldots \ldots \ldots \ldots \ldots$ L. guadeloupensis

\section{KEY TO CENTRAL AMERICAN AND MEXICAN SPECIES}

1. Basidiocarps large and white; pileus velutinous; taste acrid $\ldots \ldots \ldots \ldots \ldots \ldots \ldots \ldots \ldots \ldots$. hallingii

1. Basidiocarps not white; pileus not velutinous . . . . . 2

2. Pileus colour orange $\ldots \ldots \ldots \ldots \ldots \ldots \ldots$

2. Pileus colour greyish brown to blackish brown ... . . 4

3. Latex unchanging; pleurocystidia absent; spore ornamentation up to $0.5 \mu \mathrm{m}$ high, not forming a reticulum.

$\ldots \ldots \ldots \ldots \ldots \ldots \ldots \ldots$. veraecrucis

3. Latex staining brown; conspicuous pleurolamprocystidia; spore ornamentation up to $1-2 \mu \mathrm{m}$ high, forming a complete reticulum . . . . . pallidilamellatus

4. Latex unchanging; pleuromacrocystidia present; spore ornamentation not forming a reticulum ...... L. chiapanensis

4. Latex staining brown; pleurocystidia absent; spore ornamentation reticulate . . . . . . . fuscomarginatus

\section{Distribution of closest relative(s)}

Figure 14 shows the distribution of the closest relative(s):

i. for taxa originating from Central America or the Caribbean;

ii. according to host association of Central American and Caribbean taxa; and

iii. by altitude of those taxa.

The majority of Caribbean clades have a South American closest relative, while Central American clades show a more mixed result. Clades found associated with Fabaceae, Polygonaceae or Nyctaginaceae have closest relatives in South America, while clades found associated with Betulaceae, Fagaceae or
Pinaceae have closest relatives from North America, Asia and/ or Europe. Clades reported from altitudes lower than $500 \mathrm{~m}$ were found to have South American relatives, while clades reported from higher altitudes, mainly over $1000 \mathrm{~m}$, were found to have North American, Asian and/or European relatives.

\section{DISCUSSION}

\section{Diversity of Lactifluus spp. in the Antilles}

Studying Lactifluus diversity in the Antilles has not only revealed new species, but also a new section. The newly described section Lactifluus sect. Nebulosi contains six Lesser Antillean species, as well as $L$. chiapanensis from Mexico, and L. coccolobae and L. guanensis from the Greater Antilles (Fig. 1). The section belongs in L. subg. Gymnocarpi. In contrast to the other described sections in this subgenus that completely lack true pleurocystidia, most species of $L$. sect. Nebulosi have conspicuous pleuromacrocystidia. The section contains only Neotropical collections and is characterised by dull fruiting body colours (a brown-grey pileus and a white-grey stipe), an unpleasant fishy odour in all species except $L$. murinipes, and broadly ellipsoid spores with isolated, rounded warts up to $1 \mu \mathrm{m}$ high. This type of isolated spore ornamentation is relatively rare in the genus and is reminiscent of the African L. sect. Phlebonemi in its traditional morphological delineation, which contains the species $L$. angustus, $L$. arsenei, $L$. nonpiscis, $L$. phlebonemus and L. pisciodorus. It is noteworthy that all these species also exhibit an unpleasant and often fishy odour (Verbeken \& Walleyn 2010). Interestingly, two other Antillean species, $L$. lepus and $L$. pegleri, have isolated spore ornamentation. Both species do not belong in $L$. sect. Nebulosi, but in different sections in L. subg. Gymnocarpi and L. subg. Pseudogymnocarpi, respectively. The high proportion of this type of ornamentation in the Lesser Antilles, which occurs in eight out of eleven species with three independent origins, combined with the relatively rare occurrence globally, raises the question whether this type of spore ornamentation could represent an evolutionary advantage in the habitats of the Lesser Antilles and if it could be correlated to certain environmental variables.

Besides the six species of $L$. sect. Nebulosi, five other species were recorded, bringing the total known diversity of the Lesser Antilles to eleven Lactifluus species, although some species

\section{Distribution of closest relative(s) compared to}
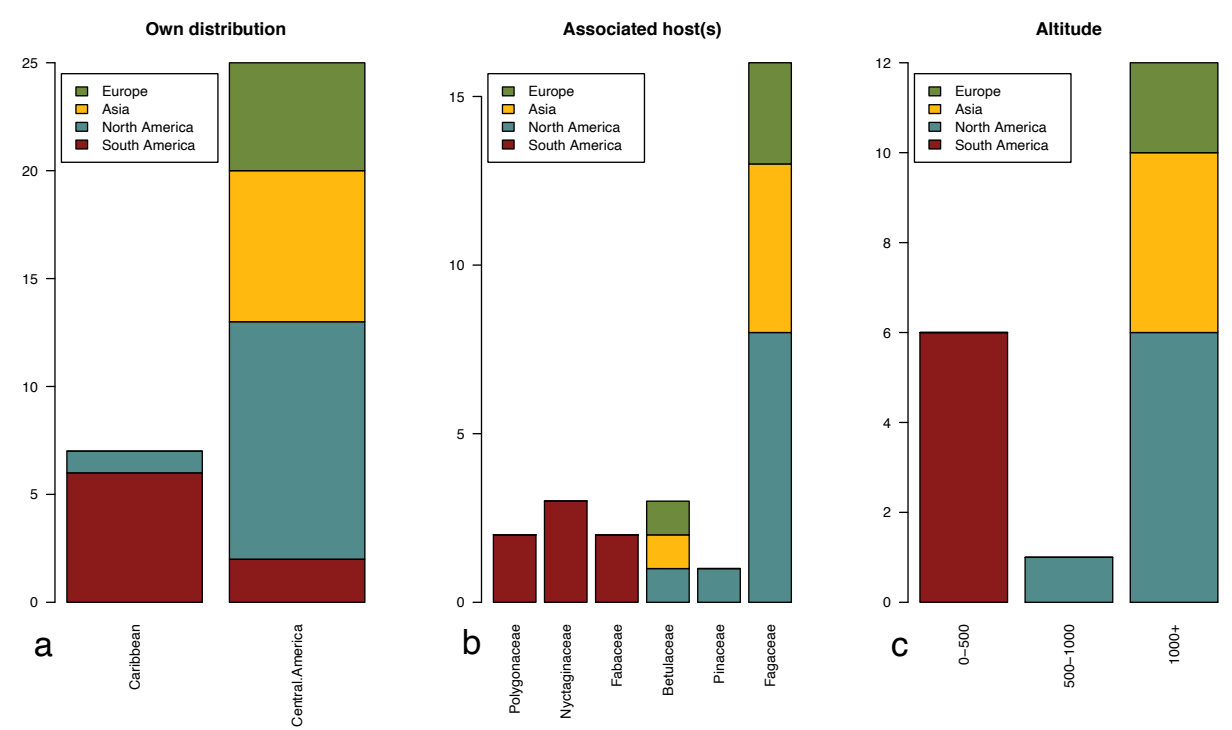

Fig. 14 Number of taxa with closest relative(s) from Europe, Asia, North America or South America compared to: a. Central American or Caribbean distribution; b. different host families of Central American and Caribbean taxa; c. different altitudes of Central American and Caribbean taxa. 
remain rare (i.e., known from only one or two collections). Even though intraspecific variation is poorly known or unknown for these rare species, we are convinced it is appropriate to describe them, given the extensive sampling and the clear morphological and molecular differences. Of the eleven species occurring in the Lesser Antilles, eight or nine have not been reported from other areas and can be classified as endemic to the Lesser Antilles. Only L. panuoides and L. venezuelanus have been reported from the mainland, from French Guiana (Fig. 1) and Venezuela (Dennis 1970), respectively. Lactifluus neotropicus might also occur in French Guiana (Fig. 1), but more research is needed to confirm this record. Lactifluus nebulosus was previously reported from the British Virgin Islands (Miller et al. 2000), but this collection (GUA-104) was shown to represent a different species: L. guanensis (Crous et al. 2019), so no overlap in Lactifluus species between the Greater Antilles and the Lesser Antilles has been found thus far. The Greater Antilles are considerably less diverse in Lactifluus species than the Lesser Antilles, with only three known species, despite the much larger surface area. Considering the small surface area of the Lesser Antilles, less than $15000 \mathrm{~km}^{2}$, these islands can be considered highly diverse in Lactifluus species. This result contrasts with an earlier observed pattern of ectomycorrhizal communities being less diverse in smaller areas (Peay et al. 2007). However, the distribution of these species across the different islands of the Lesser Antilles is still poorly studied. Given the small distances between the islands, it could be expected that most species occur on multiple islands, although it could be possible that some species are endemic to a single island. To investigate this, more sampling is needed across the archipelago.

The case of the Lesser Antilles demonstrates that sampling different forest types is important, even though in tropical climate ectomycorrhizal fungi are considered to be more abundant in xerophytic forests (Pegler \& Fiard 1983). Our results confirm the predominance of Lactifluus at the xerophytic forests of the Lesser Antilles, with about $75 \%$ of the collections originating from this type of forests. Species occurring in these forests are occasionally also found in hygrophytic or mesophytic forests, often in association with Guapira fragrans, a common host tree in xerophytic forests that can be present in mesophytic or hygrophytic forests as well. Despite their association with a host tree that is abundant in xerophytic forests, some species, such as $L$. venezuelanus, show a clear preference for mesophytic or hygrophytic forests. Other species, such as $L$. lepus, $L$. marmoratus and $L$. panuoides, are also exclusively known from these forest types. Because of the presence of these unique species, mesophytic and hygrophytic forests should not be overlooked when studying the diversity of ectomycorrhizal fungi, even though collections can be less abundant and/or less conspicuous, and therefore harder to find.

\section{Diversity of Lactifluus spp. in Central America and Mexico}

In Central America and Mexico, our phylogeny revealed the presence of at least 21 species of Lactifluus, of which only five species have been described. Many of these species occur in species complexes, such as $L$. sect. Gerardii, L. sect. Lactifluus and $L$. sect. Piperati. These sections belong to $L$. subg. Lactifluus, and no Neotropical representatives other than $L$. fuscomarginatus were reported for this subgenus before (De Crop et al. 2017). Therefore, it seems likely that these 16 unnamed clades represent new undescribed species. However, given the difficulty of delimiting species in complexes such as these, with morphological differences often being very subtle, these complexes will need detailed study to allow describing these species. Despite the limited number of described species, our phylogeny shows that there is a high diversity of Lactifluus spp. in Central America and Mexico. In addition, many species are known from only one or two collections and are originating from a limited number of regions, so it can be expected that the number of species will rise even more.

\section{Contrasting diversity patterns of Lactifluus spp. between Central America/Mexico and the Antilles}

No overlap has been found between species from Central America and Mexico and species from the Caribbean, contrary to what was detected for several other ectomycorrhizal fungi associated with Coccoloba uvifera or Pinus for example (OrtizSantana et al. 2007, Põlme et al. 2017). Moreover, some contrasting biogeographical patterns between the two regions can be observed, such as how the species are distributed. In the Antilles, 14 species were found, distributed across seven clades, while in Central America and Mexico, 20 species were found, distributed across 17 clades. This shows that there were a relatively limited number of colonisations in the Antilles, after which some clades radiated, especially $L$. sect. Nebulosi, while in Central America there were many repeated colonisations, with only limited radiation. In addition, the majority of Central American species occur in $L$. subg. Lactifluus, and the majority of Caribbean species in L. subg. Gymnocarpi. Another contrasting pattern is their different affinities, with Antillean taxa mainly showing South American affinities, and Central American and Mexican taxa mainly showing North American, Asian and European affinities (Fig. 14). Previously, the Lesser Antilles were suspected to contain Lactifluus species of both North and South American origin (Pegler \& Fiard 1983, Hackel 2014). However, the Antillean $L$. pegleri turns out to be unrelated to the North American L. hygrophoroides. In fact, all Lesser Antillean Lactifluus species are embedded within South American clades in the phylogeny (Fig. 1), so they all appear to have more recent common ancestors with South American species. Lesser Antillean species were mainly found associated with Coccoloba (Polygonaceae) and Guapira (Nyctaginaceae), both important ectomycorrhizal hosts in South America, showing that host specificity could be responsible for the South American origin of these taxa. In contrast, the three species from the Greater Antilles have mixed origins, with $L$. coccolobae and $L$. guanensis belonging to $L$. sect. Nebulosi, which consists mainly of Lesser Antillean species and has South American affinities, and $L$. domingensis having North American affinities (Fig. 1). Lactifluus coccolobae and L. guanensis were found with Coccoloba uvifera (Polygonaceae), while L. domingensis was found in montane forests with Pinus occidentalis (Pinaceae).

In Central America and Mexico on the other hand, the majority of the species were found to have North American, Asian or European affinities, and only few species were found to have South American affinities, despite being connected to this continent. Species with South American affinities are L. veraecrucis, of which the host relationship is unknown, and $L$. chiapanensis, which was found associated with Gymnopodium floribundum, a species found at low altitudes in Mexico, Guatemala and Belize. The genus Gymnopodium is only known from Central America, but belongs to the Polygonaceae family, to which also the ectomycorrhizal Coccoloba belongs. Coccoloba is distributed across Mexico, Central America, the Caribbean and South America, and was reported as a host for most other species in the same section as $L$. chiapanensis. In contrast, other Central American species were found with Carpinus (Betulaceae), Fagus or Quercus (Fagaceae), important ectomycorrhizal host genera in North America, Europe and Asia. These plant families can, however, also be found in the western mountain ranges in South America, and $L$. hallingii for example, which is associated with Quercus, was also reported from localities at high altitudes in Colombia. 


\section{Affinities of Lactifluus spp. with North and South American taxa in the light of tectonics}

The land masses of Central America arose as a result of the subduction of the Cocos plate under the Caribbean plate, with Costa Rica and Panama forming a separate block neighbouring the Nasca plate in the south and the South American plate in the southeast (Kellogg et al. 1995). The land masses emerged first in the northern part of Central America during Oligocene and Miocene, and finally the isthmus was closed probably in the area of Panama approximately until 4 million years ago (e.g., Haug et al. 2001). This process allowed plants and their fungi to move southwards from North America and to colonise Central America before the isthmus was closed, while northwards dispersal from South America was at first impeded by a broad water passage and later only possible by island hopping over an island archipelago that later fused into the land bridge of Panama.

The Antilles are located at the northern and eastern boarder of the Caribbean plate and are mostly the result of complex subduction events of the Atlantic plate underneath the Caribbean plate. The Caribbean plate originated from the Pacific on the western side of Northern South America and moved first northwards and later eastwards resulting in shear zones with the South American plate until it attained its modern aspect by the end of the Middle Eocene (Freeland \& Dietz 1971). Therefore, there were possibly more opportunities for dispersal from South America onto the Antilles than from North America. In the middle Oligocene connections between North temperate flora and at least Puerto Rico existed, as pollen records showed that for example Fagus occurred on the island (Graham \& Jarzen 1969). However, suitable habitats for the temperate flora were located at high elevation, and due to the intense erosion on Caribbean islands, those habitats have disappeared. The lower elevation of islands today could act as an additional barrier to the dispersion of North American taxa or their Central American relatives.

\section{CONCLUSIONS}

In summary, we hypothesise that host specificity, possibly at host family level, is a crucial factor causing the observed biogeographical patterns. Taxa associated with Fabaceae, Polygonaceae and Nyctaginaceae show South American affinities and taxa associated with Betulaceae, Fagaceae and Pinaceae show North American, Asian and European affinities (Fig. 14). Sampling ectomycorrhizae may help to further determine to which degree host specificity shapes Lactifluus diversity. However, since different plant taxa exhibit different distributions, the effects will also be strongly associated with abiotic factors, such as climate and altitude. We found that species occurring at low altitudes show affinities to South American taxa, and species occurring at high altitudes, in montane forests, show affinities to North American, Asian and European taxa (Fig. 14). These high altitudes have a similar climate and vegetation to temperate regions, while at low altitudes climate and vegetation are similar to tropical regions. Therefore, it is not possible to separate the effects of climate and host association, and both could be considered fundamental explanatory factors of the ability of a taxon to colonise a certain region. In addition, the different geological histories of Central America/Mexico and the Antilles may also have contributed to the contrasting diversity patterns between the regions.

These results suggest that host specificity and climate could shape phylogenetic patterns in ectomycorrhizal fungi, and encourage studying the effects of host specificity and climate on Lactifluus diversity patterns on a global scale.
Acknowledgements The first author was funded by a doctoral scholarship of the Special Research Fund (BOF, grant BOF-DOC-2015-007001). E. De Crop is supported by the 'Special Research Fund Ghent University' (BOF, grant BOF-PDO-2017-001201). The collecting trips to the Lesser Antilles (20062015) were financially supported by various organizations and structures such as ONF (French Forestry Office), DIREN, DEAL (Regional counterparts of the French Ministry for Ecology in Guadeloupe and Martinique), Regional administrations (Martinique in 2015) and Regional Parks (PNRM - Parc naturel régional de Martinique). We thank the Environmental Ministry of Panama (MiAmbiente) for issuing collection and export permits (SE/PH-4-18, SEX/H-2-18). O. Cáceres, M. Cuevas and J. Rodríguez are thanked for logistic support during fieldwork in Panama. Part of the molecular work was funded by the Laboratoire d'Excellence CEBA (ANR-10-LABX-25-01) and the Bibliothèque du vivant sequencing project. The authors thank $L$. Martinez-Suz and $B$. Dentinger for the DNA extractions of the dried collections from Kew herbarium. The authors would also like to thank P.-A. Moreau, for his collections and the picture of $L$. venezuelanus. A. Verbeken wants to thank J. Perez Moreno for organizing the fieldtrip in Mexico at the occasion of IWEMM9.

\section{REFERENCES}

Alvarez-Manjarrez J, Garibay-Orijel R, Smith ME. 2018. Caryophyllales are the main hosts of a unique set of ectomycorrhizal fungi in a Neotropical dry forest. Mycorrhiza 28: 103-115.

Beard JS. 1948. The natural vegetation of the Windward and Leeward Island. Ox For Mem.

Buyck B, Hofstetter V, Eberhardt U, et al. 2008. Walking the thin line between Russula and Lactarius: the dilemma of Russula subsect. Ochricompactae. Fungal Diversity 28: 15-40.

Buyck B, Hofstetter V, Verbeken A, et al. 2010. Proposal 1919: To conserve Lactarius nom. cons. (Basidiomycota) with a conserved type. Mycotaxon 111: $504-508$.

Crous P, Wingfield M, Lombard L, et al. 2019. Fungal Planet description sheets: 951-1041. Persoonia 44: 223-425.

De Crop E. 2016. Global phylogeny and evolutionary history of the genus Lactifluus. PhD, Biology, Ghent University, Ghent.

De Crop E, Nuytinck J, Van de Putte K, et al. 2017. A multi-gene phylogeny of Lactifluus (Basidiomycota, Russulales) translated into a new infrageneric classification of the genus. Persoonia 38: 58-80.

Delgat L, Dierickx G, De Wilde S, et al. 2019. Looks can be deceiving: the deceptive milkcaps (Lactifluus, Russulaceae) exhibit low morphological variance but harbour high genetic diversity. IMA Fungus 10: 14.

Dennis RWG. 1970. Fungus Flora of Venezuela and adjacent countries. Kew Bulletin Additional Series 111: 1-531.

Dentinger B, Margaritescu S, Moncalvo J. 2010. Rapid and reliable highthroughput methods of DNA extraction for use in barcoding and molecular systematics of mushrooms. Molecular Ecology Resources 10: 628-633.

Freeland GL, Dietz RS. 1971. Plate tectonic evolution of Caribbean - Gulf of Mexico region. Nature 232: 20-23.

Gardes M, Bruns TD. 1993. ITS primers with enhanced specificity for Basidiomycetes - application to the identification of mycorrhizae and rusts. Molecular Ecology 2: 113-118.

Graham A, Jarzen DM. 1969. Studies in neotropical paleobotany. 1. The Oligocene communities of Puerto Rico. Annals of the Missouri Botanical Garden 56: 308-357.

Hackel J. 2014. Origins and diversification of neotropical taxa in a cosmopolitan lineage of ectomycorrhizal fungi (Basidiomycota: Russulaceae). Master, Université Toulouse III - Paul Sabatier.

Haug GH, Tiedemann R, Zahn R, et al. 2001. Role of Panama uplift on oceanic freshwater balance. Geology 29: 207-210.

Joseph P. 2013. How should the forest types of the Lesser Antilles be described in the intertropical area. Earth Resources 1: 78-102.

Katoh K, Toh H. 2008. Recent developments in the MAFFT multiple sequence alignment program. Briefings in Bioinformatics 9: 286-298.

Kellogg JN, Vega V, Stallings T, et al. 1995. Tectonic development of Panama, Costa Rica, and the Colombian Andes: constraints from global positioning system geodetic studies and gravity. Special paper of the Geological Society of America 295: 75-90.

Kornerup A, Wanscher JH. 1978. Methuen handbook of colour. Methuen, London.

Lalli G, Pacioni G. 1992. Lactarius sect. Lactifluus and allied species. Mycotaxon 44: 155-195.

Lanfear R, Frandsen PB, Wright AM, et al. 2017. PartitionFinder 2: New methods for selecting partitioned models of evolution for molecular and morphological phylogenetic analyses. Molecular Biology and Evolution 34: 772-773. 
Le HT, Nuytinck J, Verbeken A, et al. 2007. Lactarius in Northern Thailand: 1. Lactarius subgenus Piperites. Fungal Diversity 24: 173-224.

Liu YJJ, Whelen S, Benjamin DH. 1999. Phylogenetic relationships among ascomycetes: Evidence from an RNA polymerase II subunit. Molecular Biology and Evolution 16: 1799-1808.

Matheny PB. 2005. Improving phylogenetic inference of mushrooms with RPB1 and RPB2 nucleotide sequences (Inocybe; Agaricales). Molecular Phylogenetics and Evolution 35: 1-20.

Matheny PB, Liu YJJ, Ammirati JF, et al. 2002. Using RPB1 sequences to improve phylogenetic inference among mushrooms (Inocybe, Agaricales). American Journal of Botany 89: 688-698.

Miller MA, Pfeiffer W, Schwartz T. 2010. Creating the CIPRES science gateway for inference of large phylogenetic trees. Proceedings of the Gateway Computing Environments Workshop (GCE): 1-8.

Miller OK, Lodge DJ, Baroni TJ. 2000. New and interesting ectomycorrhizal fungi from Puerto Rico, Mona, and Guana Islands. Mycologia 92: 558-570.

Miller SL, Aime MC, Henkel TW. 2002. Russulaceae of the Pakaraima Mountains of Guyana 1. New species of pleurotoid Lactarius. Mycologia 94: 545-553.

Miller SL, Aime MC, Henkel TW. 2012. Russulaceae of the Pakaraima Mountains of Guyana 2. New species of Russula and Lactifluus. Mycotaxon 121: 233-253.

Moncalvo JM, Lutzoni FM, Rehner SA, et al. 2000. Phylogenetic relationships of agaric fungi based on nuclear large subunit ribosomal DNA sequences. Systematic Biology 49: 278-305.

Montoya L, Bandala VM. 2004. Studies on Lactarius: a new species from the Gulf of Mexico area. Cryptogamie Mycologie 25: 15-21.

Montoya L, Bandala VM, Guzmán G. 1996. New and interesting species of Lactarius from Mexico including scanning electron microscope observations. Mycotaxon 57: 411-424.

Montoya L, Bandala VM, Haug I, et al. 2012. A new species of Lactarius (subgenus Gerardii) from two relict Fagus grandifolia var. mexicana populations in Mexican montane cloud forests. Mycologia 104: 175-181.

Nuytinck J, Verbeken A. 2003. Lactarius sanguifluus versus Lactarius vinosus - molecular and morphological analyses. Mycological Progress 2: 227-234.

Ortiz-Santana B, Lodge DJ, Baroni TJ, et al. 2007. Boletes from Belize and the Dominican Republic. Fungal Diversity 27: 247-416.

Panagopoulos N. 1999. A guide to Caribbean vegetation types: Preliminary classification systems and descriptions. Nature Conservancy.

Peay KG, Bruns TD, Kennedy PG, et al. 2007. A strong species-area relationship for eukaryotic soil microbes: island size matters for ectomycorrhizal fungi. Ecology Letters 10: 470-480.

Pegler DN, Fiard JP. 1979. Taxonomy and ecology of Lactarius (Agaricales) in the Lesser Antilles. Kew Bulletin 33: 601-628.

Pegler DN, Fiard JP. 1983. Agaric Flora of the Lesser Antilles. HMSO, London.

Põlme S, Bahram M, Kõljalg U, et al. 2017. Biogeography and specificity of ectomycorrhizal fungi of Coccoloba uvifera. Biogeography of mycorrhizal symbiosis: $345-359$. Springer.
R Core Team. 2018. R: A language and environment for statistical computing. R Foundation for Statistical Computing, Vienna, Austria. http://www.Rproject.org/ [accessed 14 June 2019].

Singer R. 1952. Russulaceae of Trinidad and Venezuela. Kew Bulletin 7: 295-301.

Singer R. 1973. Diagnoses Fungorum Novorum Agaricalium III. Beihefte Sydowia 7: 1-106.

Singer R, Araujo I, Ivory MH. 1983. The ectotropically mycorrhizal fungi of the neotropical lowlands, especially Central Amazonia. (Litter decomposition and ectomycorrhiza in Amazonian forests 2). Beihefte zur Nova Hedwigia 77: 1-352.

Stamatakis A. 2014. RAxML version 8: a tool for phylogenetic analysis and post-analysis of large phylogenies. Bioinformatics 30: 1312-1313.

Stamatakis A, Hoover P, Rougemont J. 2008. A rapid bootstrap algorithm for the RAxML web servers. Systematic Biology 57: 758-771.

Stehle H. 1947. La végétation sylvatique de l'Archipel Caraïbe.

Stiller JW, Hall BD. 1997. The origin of red algae: Implications for plasmid evolution. Proceedings of the National Academy of Sciences of the United States of America 94: 4520-4525.

Stubbe D, Nuytinck J, Verbeken A. 2010. Critical assessment of the Lactarius gerardii species complex (Russulales). Fungal Biology 114: 271-283.

Tamura K, Stecher G, Peterson D, et al. 2013. MEGA6: Molecular evolutionary genetics analysis version 6.0. Molecular Biology and Evolution 30: $2725-2729$.

Tedersoo L, Sadam A, Zambrano M, et al. 2010. Low diversity and high host preference of ectomycorrhizal fungi in Western Amazonia, a neotropical biodiversity hotspot. Isme Journal 4: 465-471.

Tel-Zur N, Abbo S, Myslabodski D, et al. 1999. Modified CTAB procedure for DNA isolation from epiphytic cacti of the genera Hylocereus and Selenicereus (Cactaceae). Plant Molecular Biology Reporter 17: 249-254.

Van de Putte K. 2012. Hidden diversity exposed: A case study of Lactifluus volemus sensu lato. PhD, Biology, Ghent University, Ghent.

Van de Putte K, Nuytinck J, De Crop E, et al. 2016. Lactifluus volemus in Europe: three species in one - revealed by a multilocus genealogical approach, Bayesian species delimitation and morphology. Fungal Biology 120: 1-25.

Van de Putte K, Nuytinck J, Stubbe D, et al. 2010. Lactarius volemus sensu lato (Russulales) from northern Thailand: morphological and phylogenetic species concepts explored. Fungal Diversity 45: 99-130.

Verbeken A, Van de Putte K, De Crop E. 2012. New combinations in Lactifluus. 3. L. subgenera Lactifluus and Piperati. Mycotaxon 120: 443-450. Verbeken A, Walleyn R. 2010. Monograph of Lactarius in tropical Africa. Fungus Flora of Tropical Africa, National Botanic Garden, Belgium: 161 +154 plates.

White TJ, Bruns T, Lee S, et al. 1990. Amplification and direct sequencing of fungal ribosomal RNA genes for phylogenetics. In: Innis MA, Gelfand $\mathrm{DH}$, Sninsky JJ, et al. (eds), PCR protocols: a guide to methods and applications: 315-322. Academic Press, New York. 